\title{
Seismic source characterization of the Alpine foreland in the context of a probabilistic seismic hazard analysis by PEGASOS Expert Group 1 (EG1a)
}

\author{
STEFAN M. SCHMID ${ }^{1} \&$ DARIO SLEJKO ${ }^{2}$
}

Key words: earthquakes, seismic hazard, seismic sources, probabilistic analysis, Alpine foreland

\begin{abstract}
Seismic source characterization is performed as part of the PEGASOS project for the assessment of the seismic hazard at the 4 sites of the Swiss Nuclear Power Plants. The analysis is performed according to the Level 4 procedures for expert elicitation defined in the guidelines of the US Nuclear Regulatory Committee whereby the quantification of uncertainties plays a crucial role. According to our analysis, which is one amongst four that were performed in the frame of PEGASOS, the most important epistemic uncertainty is related to the question as to weather basement-rooted faults at the margins of pre-existing Permo-Carboniferous troughs are prone for compressive or transpressive reactivation under the present-day stress field or not. The question after the present-day style of deformation in the Alpine foreland (thick-skinned versus thin-skinned) is closely related to this key question. Together with the consideration of uncertainties regarding the mapping of seismogenic zones and/or line sources alternative zonations are presented in form of a logic tree with 21 branches. Area sources play
\end{abstract}

a predominant role in the working area located at the margin of a diffuse plate boundary.

Earthquake recurrence relationships are discussed by taking into account a series of uncertainties. These concern the evaluation of $b$-values and the evaluation of $a$-values once the $b$-values were fixed. Both parameters in the Gutenberg-Richter law are based on non-perfect and incomplete catalogue data that were carefully analysed beforehand. Since PEGASOS demanded an analysis of annual probabilities down to one event in $10^{7}$ years, the question after the value of the maximum possible earthquake magnitude $M_{\max }$ and related error in $M_{\max }$ estimates plays a crucial role. We estimate $M_{\max }$ by using geological as well as statistical methods. $M_{\max }=6.9$ cannot be excluded in most areas, in the Basel area $M_{\max }=7.3$ is possible. Uncertainties in $a, b$ and $M_{\max }$ are again discussed in form of a logic tree, this time with 18 branches. Hence the final logic tree has 378 branches and represents the seismic source characterization input into PSHA that takes account of all uncertainties we are aware of.

\section{Introduction}

The Mediterranean-Alpine region of Cenozoic orogens (Fig. 1), which partly extends into our area of investigation (Fig. 2), represents a diffuse and broad plate boundary governed by the relative motion between the African and Eurasian plates (e.g. Meletti et al. 2000). Location and deep structure of the Alps resulted from continent-continent collision, the Adriatic promontory acting as a rigid indenting microplate (e.g. Schmid \& Kissling 2000; Schmid et al. 2004a, 2004b). Collision produced a cold, dense, slowly subsiding lithospheric root beneath the mountain chain. The present-day Alpine uplift (1-2 mm/year) is driven by isostatic rebound of the crustal and mantle lithospheric roots (Kissling pers. comm.; Kissling 2007). The Moho in Switzerland varies from $28 \mathrm{~km}$ in the northwestern sector to some $60 \mathrm{~km}$ under the Insubric line (Müller 1984a, 1984b; Waldhauser et al. 1998). From updated processing of reflection and refraction data (Waldhauser et al. 1998) a southward continuation of the European Moho below the Adriatic Moho, although not detected, seems plausible. The 3D model of Waldhauser et al. (1998) proposes that the European Moho subducted below the Adriatic Moho, while the latter under-thrusted the Ligurian Moho (see also Schmid et al. 2004b).

Earthquakes are considered an important natural hazard in Switzerland. They are basically a manifestation of the ongoing tectonic activity between the Alps in the south and the Cenozoic Rift System, e.g. the Rhine Graben (e.g. Dèzes et al. 2004) to the north. Over the past 700 years, a total of 28 events of a magnitude $M w$ larger than, or equal to, 5.5 have occurred (Fäh et al. 2003; $M w=$ moment magnitude; throughout this paper we use $M w$ when referring to magnitude); twelve of them caused severe damage (intensity of VIII EMS or higher). Nevertheless, on a worldwide scale the seismicity in Switzerland and surrounding areas may be considered low to medium. Three

${ }^{1}$ Geologisch-Paläontologisches Institut, University of Basel, Switzerland.

${ }^{2}$ Istituto Nazionale di Oceanografia e di Geofisica Sperimentale, Trieste, Italy. 


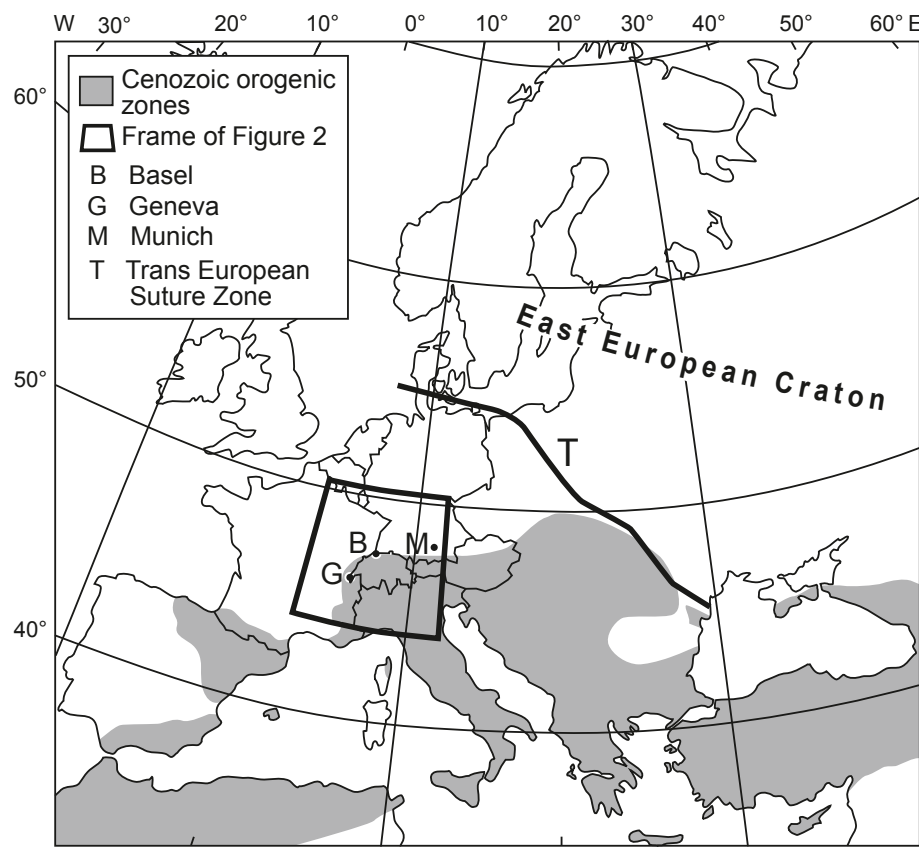

Fig. 1. Location of the study area in a boundary area between the consolidated European foreland and the younger and mobile Cenozoic orogenic zones.

main seismic areas in Switzerland (Fig. 3) were identified already based on the analysis of the 1972-1978 low seismicity $(1.5<\mathrm{M}<4.0)$ : Valais, Engadine, and Basel (Mayer-Rosa \& Müller 1979), while the central part of the country was considered almost aseismic (Pavoni 1977) although a swarm with maximum magnitude 5 occurred in 1964 near Lucerne. The largest historical earthquakes interested Basel in 1356 (magnitude estimated between 6.2 and 6.9 by various authors; i.e. Laubscher 2006), Valais, Lucerne, Chur, and Neuchâtel, and the Rhine valley at the border with Austria. The majority of fault plane solutions (Mayer-Rosa \& Müller 1979; Jimenez \& Pavoni 1984; Kastrup et al. 2004) are of strike-slip type with a NW-SE oriented compressive axis (Fig. 4); a few mechanisms are of thrust type. Strike slip mechanisms are in agreement with the left and right lateral strike slip faults in the Valais region (Pavoni 1980a) and with the in situ stress measurements at the southern end of the Rhine Graben near Basel (Becker 1999, 2000). In general, the NW-SE oriented maximum compressive stress is in agreement with the in situ measurements and corresponds with the orientation of the maximum horizontal crustal shortening; hence, it can be considered as constant over the last 10 million years (Pavoni 1980b). This stress pattern was confirmed also by low magnitude earthquakes in the Sanetschpass region (Franck et al. 1984).

The first probabilistic seismic hazard assessment (PSHA) for Switzerland was published in 1978 (Sägesser \& Mayer-Rosa 1978). Hazard was expressed in terms of macroseismic intensity based on the Cornell (1968) approach, with a zoning model of about 20 zones, which to a large degree mirrored the spatial distribution of seismicity. That study was the basis for the Swiss building code as well as for critical facilities, such as nuclear power plants (NPPs) and large dams. The seismogenic source model used by Müller \& Mayer-Rosa (1980) in the new seismic hazard maps of Switzerland was based on a complete analysis of the seismicity in the context of the regional tectonic setting. Fourteen zones on the Swiss territory and eight outside were considered. Ground motion was represented in terms of macroseismic intensity, and from that map a schematic zoning map was then derived. Also the Meletti et al. (2000) seismogenic zonation, used for the seismic hazard map of Italy for the building code (Slejko et al. 1998), considered two seismic sources in Switzerland for their influence to Italy: Valais and Engadine.

In 1995 a comprehensive study by Rüttener (1995), based on a historical parametric method, estimated the hazard and associated uncertainties at twelve sites within Switzerland. Again, the computed parameter was macroseismic intensity. Grünthal et al. (1998) slightly updated the hazard map, and provided a harmonized assessment between Germany, Austria and Switzerland (D-A-CH). This D-A-CH map was used as input for the Global Seismic Hazard Assessment Program (GSHAP; Giardini et al. 1999). In 2002, the SESAME project (Seismotectonics and Seismic Hazard Assessment in the Mediterranean Region) published a first unified seismic hazard model for the European-Mediterranean region (Jimenez et al. 2001, 2003). For SESAME computations, the Ambraseys et al. (1996) relationships in terms of peak ground acceleration (PGA) and spectral acceleration (SA) were considered to be appropriate for the regional hazard assessment, since they were obtained on the basis of a European-wide strong motion data set with magnitudes ranging between 4.0 and 7.9 and four categories of soil condition (bedrock; stiff, soft, and very soft soil). In 2002, the results of several studies developed in Switzerland contributed to a new PSHA, a seismic hazard map that was used as input for the seismic zoning of Switzerland when developing the new Swiss building code (SIA 2003). This 2002 PSHA represented a preferred consensus model and did not include a full logic-tree approach. A new generation of hazard maps for Switzerland was prepared by Giardini et al. (2004). In that study, the spectral accelerations for frequencies 0.5 to $10 \mathrm{~Hz}$ are computed and aleatory and epistemic uncertainties considered. Two models of area sources are used: the first is based mainly on the historical and instrumental seismicity, the second is guided largely by tectonic principles and expresses the alterative view that seismicity is less stationary and thus future activity may occur in previously quiet regions.

In the course of the compulsory re-evaluation of the Swiss NPPs with respect to all safety aspects, the PEGASOS ('Probabilistische Erdbeben-Gefährdungs-Analyse für die KKW Stand-Orte in der Schweiz') project (2000-2004) was performed to provide an updated ground motion at the sites of the four Swiss NPPs: Mühleberg (KKM), Gösgen (KKG), Beznau (KKB) and Leibstadt (KKL). The latter three are located relatively close together in northern Switzerland; KKM is located about $100 \mathrm{~km}$ to the southwest (Fig. 5). Earlier experience had shown that to a large extend the results of these

122 S. M. Schmid \& D. Slejko 


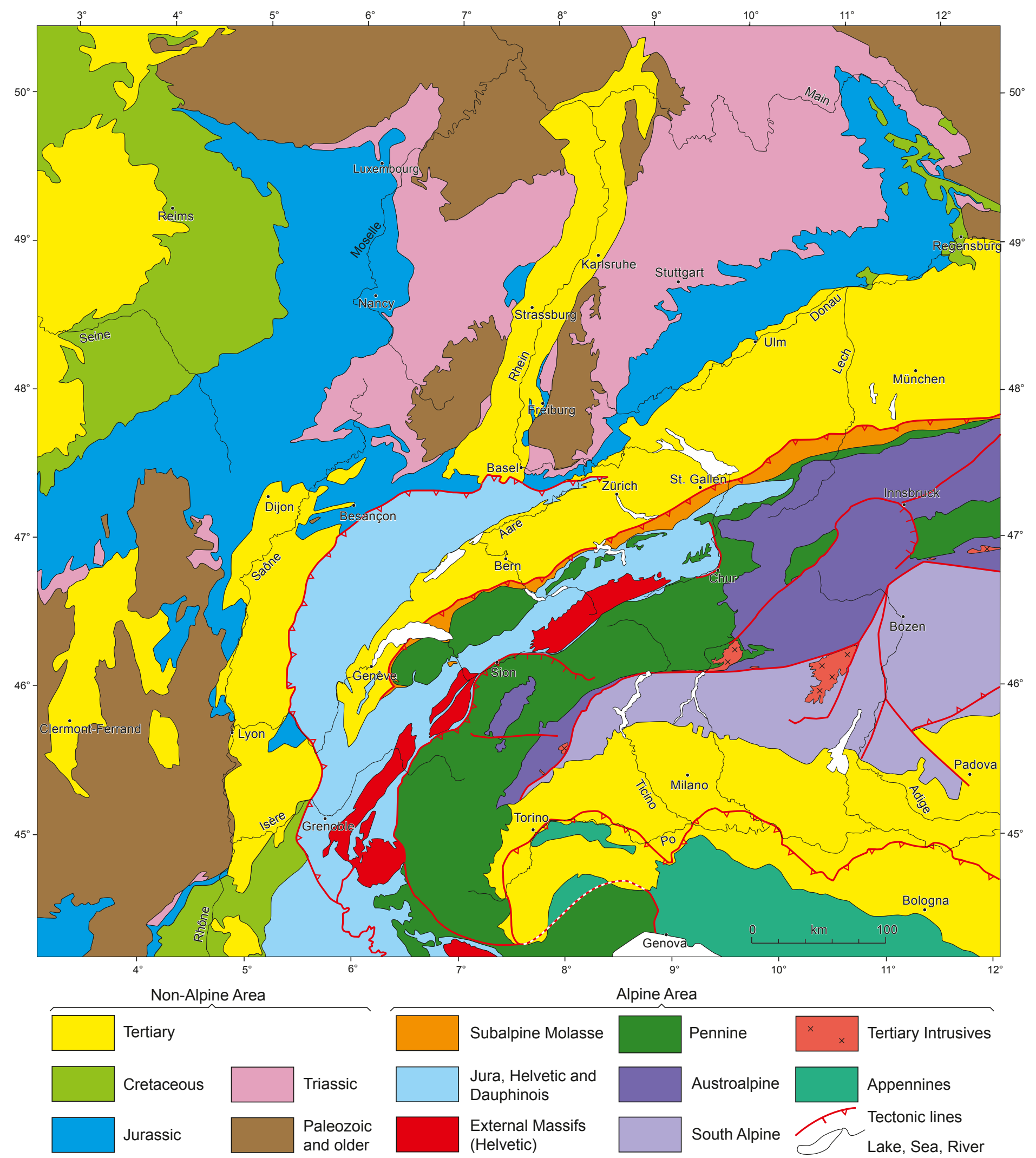

Fig. 2. Geological-tectonic map of the study area, see Fig. 1 for location. Outlines taken from this same map were transferred to the maps depicted in Figs. 5, 6, 8,9 and 14 . 


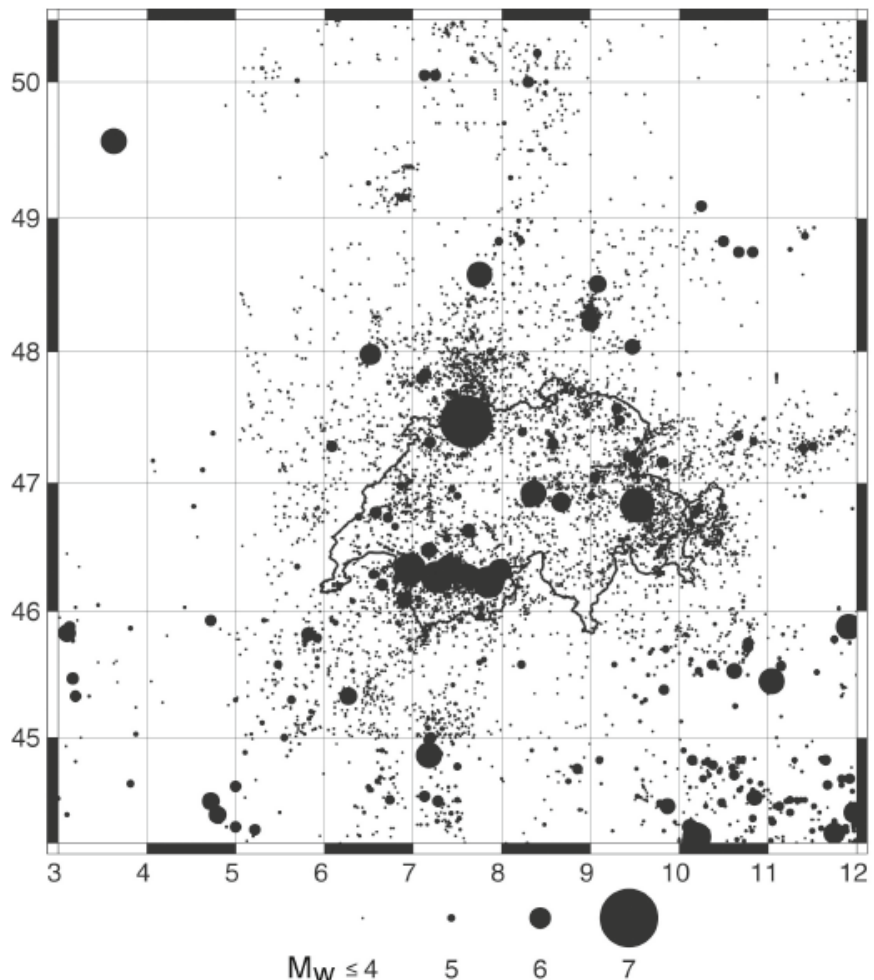

Fig. 3. Epicentre map of those events of the ECOS catalogue (Fäh et al. 2003) that were considered in this study after removal of dubious events and aftershocks (see text). Size of black circles is scaled according to $M_{w}$ for events with an $M_{w} \geq 4$. Note that events recorded in the ECOS catalogue, and consequently the epicentres shown in this figure, are only complete for Switzerland and immediately adjacent areas, i.e. between $5.6^{\circ}$ to $11.1^{\circ}$ east and $45.4^{\circ}$ to $58.3^{\circ}$ north.

studies are driven by the results of the seismic hazard analysis. The complete study (NAGRA 2004) was performed according to the Level 4 procedures for expert elicitation defined in the guidelines of the Senior Seismic Hazard Assessment Committee (SSHAC 1997) on behalf of the U.S. Nuclear Regulatory Committee (Coppersmith et al. 2008). This was only the second time, after the study for the nuclear waste repository at Yucca Mountain (Nevada USA), that this procedure based on the use of experts and the assessment of epistemic and aleatory uncertainties (Stepp et al. 2001) is applied.

The quantification of uncertainties (McGuire 1977) is a crucial point in modern PSHA. Two kinds of uncertainties characterise the results in PSHA: the aleatory variability and the epistemic uncertainty (McGuire \& Shedlock 1981; Toro et al. 1997). Aleatory variability is the natural randomness in a process. It is considered in PSHA taking into account the standard deviation of the relation describing the process. Epistemic uncertainty is the scientific uncertainty in the model of the process and is due to limited data and knowledge as well as differing interpretations. In PSHA epistemic uncertainty is taken into account by using alternative models proposed by different groups of scientists (Coppersmith et al. 2008). The logic tree approach for PSHA (Kulkarni et al. 1984; Coppersmith \& Youngs 1986) has been introduced for quantifying such epistemic uncertainties. Each node of the logic tree collects a series of choices, represented by each branch of the logic tree. The final aggregate result is obtained by weighting adequately the individual results coming from the different branches (see discussion in Rebez \& Slejko 2004).

This paper summarizes the work done by one of the four teams involved in the PEGASOS project (Coppersmith et al. 2008, NAGRA 2004). Our team independently performed its own comprehensive analysis of the geological and geophysical data, as did the three other teams (Burkhard \& Grünthal 2008; Musson et al. 2008; Wiemer et al. 2008). In this contribution we will define alternative models for some sectors of the study region. These models, with their weights, form the branches of the logic tree our team proposes for PSHA.

\section{Seismotectonic framework}

\subsection{Definition of seismic sources}

The definition of seismogenic sources needs to be based on geological and seismological data. Only in rare cases, such as along discrete plate boundaries, does a direct correlation between the two pieces of information lead to the identification of a particular tectonic structure causing the documented seismic activity. In the area of investigation, however, geology identifies a widely scattered network of tectonic structures, which formed in the geological past (Fig. 2). At present, parts of this network may or may not be seismically active. Hence, seismicity within the area of interest is characterized by widely scattered earthquake foci, associated with the reactivation of a pre-existing fault network. Moreover, the deep geometry of individual faults is frequently unknown.

In spite of these difficulties, the definition of a general kinematic framework provides a link between geology and seismicity, leading to the identification of seismotectonic regions with homogeneous behaviour. In general, active fault populations are diffusely distributed, causing earthquakes covering a wider area ("area sources"). Only in very rare cases can regions be identified, which collect the activity along one particular presently active fault ("line sources"). This is because most of the seismicity in the area of investigation is proposed to be associated with the reactivation of a network of pre-existing faults, located within particular source areas with assumed homogeneous behaviour. These networks were generated during past tectonic events and their reactivation is governed by the present-day stress regime (Fig. 4).

\subsection{Fault systems that are prone for reactivation}

In the neighbourhood of the Swiss NPPs of central and northern Switzerland, the following fault systems, rooting within the crystalline (pre-Triassic) basement, and formed in the geological past under a variety of paleo-stress fields, are prone for reactivation in the present-day stress field (Fig. 4). The question

124 S. M. Schmid \& D. Slejko 


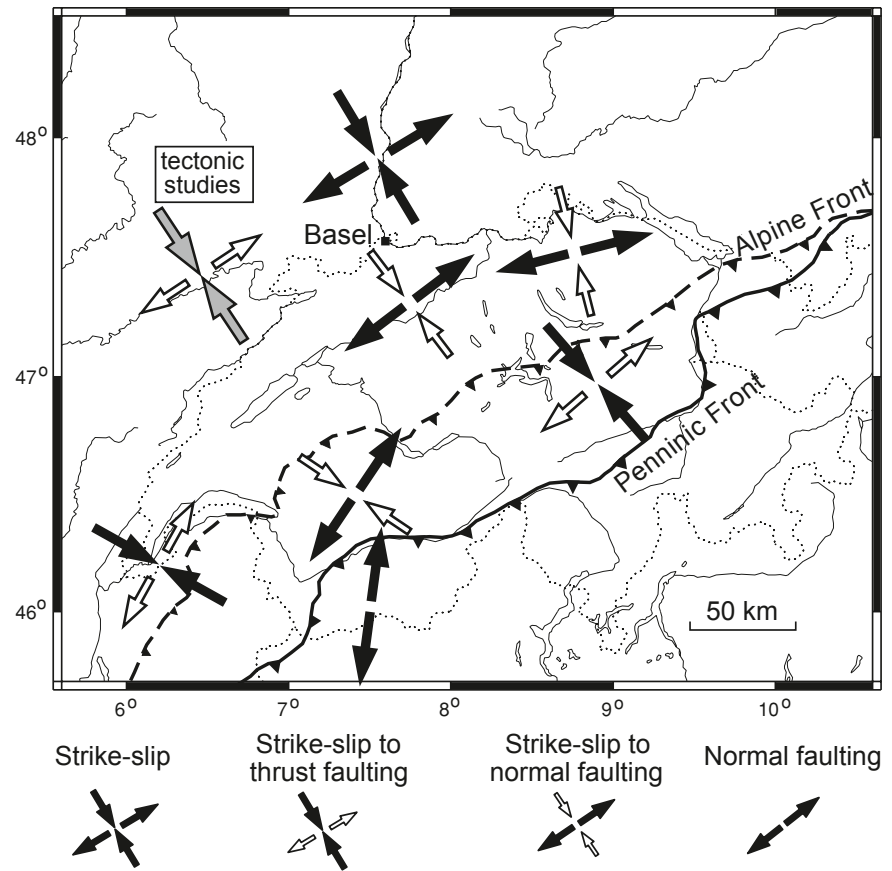

Fig. 4. Present-day stress regime inferred, where available, from the results of stress inversions of earthquake fault plane solutions (after Kastrup et al. 2004) and from (neo-) tectonic studies (after Ustaszewski \& Schmid 2007 and Madritsch et al. 2008) in case of the area west of Basel.

whether such reactivation will take place depends on the capability of the present-day stress field to overcome frictional resistance across such pre-existing faults. This in turn depends on the orientation of the pre-existing faults with respect to the present-day stress field, as well as on the magnitude of the pore pressure.

The Rhinish system strikes NNE-SSW. It essentially formed during Late Eocene to Oligocene Rhine and Bresse graben formation (Schumacher 2002; Dèzes et al. 2004; Ustaszewski et al. 2005a, 2005b). This fault system is suitably oriented for sinistral reactivation, given the present day stress regime as revealed from seismotectonics (Kastrup 2002; Kastrup et al. 2004).

The Hercynic system strikes NW-SE; the Vorwald (Müller et al.2002) or Neuhausen (Marchant et al.2005) faults are good examples. The fault system formed and was reactivated during a series of geological periods, i.e. Variscan orogeny, formation of Permo-Carboniferous troughs, Miocene-age movements (e.g. Müller et al. 2002). This fault system is prone for tensile and/or dextrally transtensive reactivation in the present-day stress field (Kastrup et al. 2004).

The Permo-Carboniferous (PC) trough system with its ENE-WSW strike, pre-formed during Variscan orogeny, was predominantly active during Late Carboniferous to Permian graben formation in a dextrally transtensive regime (Schumacher 2002). It was reactivated a third time in sinistral transtension during Cenozoic rifting (Ustaszewski et al. 2005a). This fault system is suitable for thrust reactivation only, given the present-day stress field (Fig. 4; Kastrup et al. 2004). However, most fault plane solutions of recent low magnitude earthquakes, mainly available from the Black Forest area and the eastern parts of the Rhine Graben, do not provide evidence for presently active thrusting by reactivation of this $\mathrm{PC}$ through system (Deichmann et al. 2000). On the other hand, new seismotectonic and local tomography data from the French part of the southern Rhine Graben (Lopes Cardozo \& Granet 2003) and geological-morphological data on neotectonic activity (Giamboni et al. 2004; Ustaszewski \& Schmid 2006, 2007) do suggest presently ongoing inversion of the PC trough system by thrusting west of the Basel area (Fig. 4).

\subsection{Thick-skinned versus thin-skinned scenarios for northern Switzerland}

The question as to how far past and/or present-day tectonic activity in the northern Alpine foreland is dominated by a thickor thin-skinned style, respectively, is still highly debated. However, this question is of fundamental importance for PSHA in northern Switzerland and adjacent areas. With "thick-skinned tectonics" it is intended that basement and cover were shortened by equal amounts within a given area. Although local decoupling between basement and cover may occur (see evidence from in situ stress data obtained in drill hole Schafisheim; Müller et al.1987), it would be of minor importance in this scenario (Ustaszewski \& Schmid, 2007). With "thin-skinned tectonics", on the other hand, it is intended that the sediments ("thin skin" of the Earth's crust) are totally detached from the basement along a décollement horizon. When applied to the Alps-Jura system, this implies that shortening in the sediments, as observable in the Jura Mountains, does not affect the basement underneath these Jura folds (e.g. Laubscher 1961). The corresponding shortening within the basement would take place much further to the south, i.e. at the front of the Alps. This model demands "distant push" enabled by through-going kinematic and mechanical decoupling across a ductile horizon at the basementcover interface, Triassic evaporites and/or shales in case of the Jura Mountains (Laubscher 1961, 1972; Burkhard 1990; Jordan 1992; Burkhard \& Sommaruga 1998). Choosing between the two scenarios when addressing ongoing (neotectonic) activity has severe implications regarding the potential reactivation of basement faults located below the "thin skin" of sediments in northern Switzerland, as well as the reactivation potential of faults located in the upper "skin".

Regarding the thick- and thin-skinned scenarios, different authors proposed three variants so far.

1. Thick-skinned model s.str. Geological-geomorphologic data from the southern part of the Rhine Graben west of Basel (Ajoie area; Giamboni et al. 2004; Ustaszewski \& Schmid 2007), as well as borehole, seismic and seismological data from underneath the Molasse basin (i.e. Fribourg fault; Meyer 1994a, 1994b; Kastrup et al. 2007) do indicate that compression, reactivating the PC trough system (transpression and/or thrusting) 
presently affects the basement underneath the décollement horizon. Hence, neotectonic deformation observable within the sediments exposed at the Earth's surface also affects the underlying basement. Note that this evidence for present-day deformation as being thick-skinned does not exclude a thin-skinned origin of the main structures within the Jura Mountains, which formed in the geological past, a postulate that is undisputed amongst most (but not all) authors (see discussion in Ustaszewski \& Schmid 2007). Seismotectonic evidence for compressive reactivation of the $\mathrm{PC}$ trough system in terms of fault plane solutions is very scarce so far. Nevertheless a thrusting $M_{W} 4.6$ event occurred in 2004 near Besançon (Baer et al. 2005), and given the geological evidences discussed above, a compressive reactivation should not be excluded. It is also feasible, for example, that thrust-related or transpressive earthquakes have a very long return period (such as potentially the strong Basel 1356 earthquake); hence they could be underrepresented by the present-day and instrumentally monitored activity.

2. Thick-skinned model s.l. ("Pavoni-model"). This model, originally proposed by Pavoni (1961) in order to explain the structures produced during the main Miocene-age phase of Jura tectonics, proposes that pure strike-slip motion without any component of compression within the basement may induce folding of the sediments located above a decoupling horizon (i.e. the Triassic evaporites). This model is thick-skinned in the sense that deformation of the cover directly roots in the basement below this cover. On the other hand, the style of deformation is completely different in cover and basement: distributed deformation by folding in the cover is taken up by localized strike-slip within the basement. Of course, this model can be modified towards, or may even become identical with the above-mentioned thick-skinned s.str.model, if one assumes strike slip motion in the basement to be transpressive, such as actually observed along the Fribourg Fault (Meyer 1994b; Kastrup et al. 2007) and inferred for the Ajoie area (Giamboni et al. 2004). Hence, this "Pavoni-model" has to be very seriously considered for presently ongoing tectonics although it was originally proposed for the main (Miocene) phase of Jura-tectonics.

3. Thin-skinned model. Müller et al. (2002) argued, based on an evaluation of the neotectonic activity in NE Switzerland (i.e. the area east of Basel), that thin-skinned deformation is still ongoing. This view is additionally supported by seismotectonic data (Kastrup et al. 2004), indicating that thrusting is restricted to the northern rim of the Alps while the basement of the foreland deforms by strike-slip motion and/or normal faulting. Hence, the type of deformation appears to be different in basement (transtension) and cover (transpression or thrusting) in the northern foreland of the Alps (Molasse basin and Jura Mountains), at least within the area covered by the seismotectonic data, which are presently available. Also, it is not unreasonable to assume that thin-skinned Jura-folding (which started at about $13 \mathrm{Ma}$ ago) is still ongoing at the present day.
From the analysis of all the data available, we conclude that all three models appear plausible. Regarding the definition of seismic sources for hazard assessment, the decision in favour of one or the other of the models is not crucial in as far as seismicity is documented to predominantly occur below the "thin skin" anyway. In fact, there is no evidence for a higher seismic activity to take place within the sediments located above the décollement horizon, as opposed to the basement below this horizon. This argues against the thin-skinned model, and hence we give slight preference to the thick-skinned model s.l..

In case of the two thick-skinned models, seismic activity in the basement would be associated with whole crustal shortening in the northern Alpine foreland. Note that this crustal shortening would have to be suspected, because the seismotectonic evidence does not convincingly document it. In case of the thin-skinned model, the Alpine foreland would be subjected to strike slip motion and/or transtension only.

We conclude that seismotectonic data (obtained on low magnitude earthquakes) indicate that there is no, or only very little, thrusting activity north of the front of the Alps. On the other hand geologists report post-2.6 Ma folding activity west of Basel (Giamboni et al. 2004; Ustaszewski \& Schmid 2007), while Graf (in Müller et al. 2002) reported activity along the Mandach thrust in the easternmost Jura west of Basel after deposition of 2 Ma old Quaternary gravels. This leads to also considering the possibility that thrusting activity might be restricted to high magnitude earthquakes with a very long return period. Because the latter accumulate more strain over geological times, compared to large numbers of small earthquakes, they could possibly have remained undetected by the seismotectonic analysis which is based on instrumental data from the earthquake catalogues only. The question, as to how well seismotectonic data represent the stress and strain field, remains open.

The uncertainty regarding the three models discussed above will flow into a decision when evaluating the probability that the PC troughs are reactivated (respectively not reactivated) by presently active thrusting and/or transpression in the northern foreland of the Alps.

\subsection{Which fault is associated with the 1356 high magnitude Basel earthquake?}

In a PSHA addressing the Swiss NPPs in northern Switzerland the question as to which fault accommodated this nearby high magnitude earthquake is highly relevant. Recently, Meghraoui et al. (2001) provided evidence that the presently active Reinach Fault (RF), located immediately south of Basel (RF in Figs. 8 \& 9 that will be discussed later), has to be associated with this historical high-magnitude Basel earthquake of 1356. Based on numerous inspections of the trench across this supposed normal fault and its re-interpretation as a gravitationally induced slide, we consider the evidence provided by Meghraoui et al. (2001) to be rather unlikely. We agree with Laubscher $(2006,2007)$ in that a reactivation of a Rhinish fault such as the

126 S. M. Schmid \& D. Slejko 
RF during the Basel earthquake in extensional mode, as was claimed by Meghraoui et al. (2001), is rather incompatible with our knowledge about the present-day stress field (Kastrup et al. 2004).

We conclude that location and orientation of the causative fault of the Basel 1356 earthquake remain unknown. However, because the Basel area is dominated by long segments of Rhinish and PC trough systems, it is most likely that of one of these two fault systems was activated during this high magnitude earthquake. As discussed in Ustaszewski \& Schmid (2007) a dextrally transpressive reactivation of a fault that is part of the PC trough system, i.e. the ENE striking Rhine-Bresse Transfer Zone (Madritsch et al.2008), is a possible candidate for having caused the 1356 Basel earthquake, as well as a reactivation of a segment of the NNE-striking Rhinish system, but in sinistral strike slip, rather than normal fault mode.

\subsection{Large-scale kinematic framework}

Regarding the area to be considered by PSHA (Fig. 2), encompassing a very large area surrounding the NPPs, a large-scale kinematic framework on a plate tectonics scale is established first. This framework closely follows that of Meletti et al. (2000) regarding northern Italy, and that of Schmid \& Kissling (2000) regarding the Western Alps. The use of a conceptual model for the larger study area is feasible because the kinematic framework is fairly well known from the works of Meletti et al. (2000) regarding the motion of the Adria plate, that of Schmid \& Kissling (2000) regarding the Alps and that of Müller et al. (2002) regarding northern and north-eastern Switzerland. There is good evidence that the Late Miocene to recent tectonic processes also control present and future seismicity. Hence many, but not all, elements of this kinematic framework are applicable to contemporary seismicity. The Friuli and Valais earthquake areas are good examples for this.

\subsection{Map of the major Neotectonic Kinematic Provinces}

The map of Fig. 5 is solely based on the large-scale kinematic framework of neotectonic activity outlined above and serves as a first step towards the definition of the seismogenic sources for Switzerland and neighbouring regions. In two further steps, the subdivision of these Neotectonic Kinematic Provinces (NKPs) into smaller areas will finally lead to the definition of seismic source areas. These further steps will additionally take into account seismotectonic evidence and present-day seismicity, respectively.

The motion and push of the Adria microplate towards the WNW, associated with dextral transpression along its northern margin, i.e. the Central Alps, lead to the identification of the following 6 NKPs labelled A to F in Fig. 5.

NKP A (Apennines). This unit is bounded by the presently active northern front of the Apennine to the north (Adria plate) and by a sinistrally transpressive western limit (contact with the

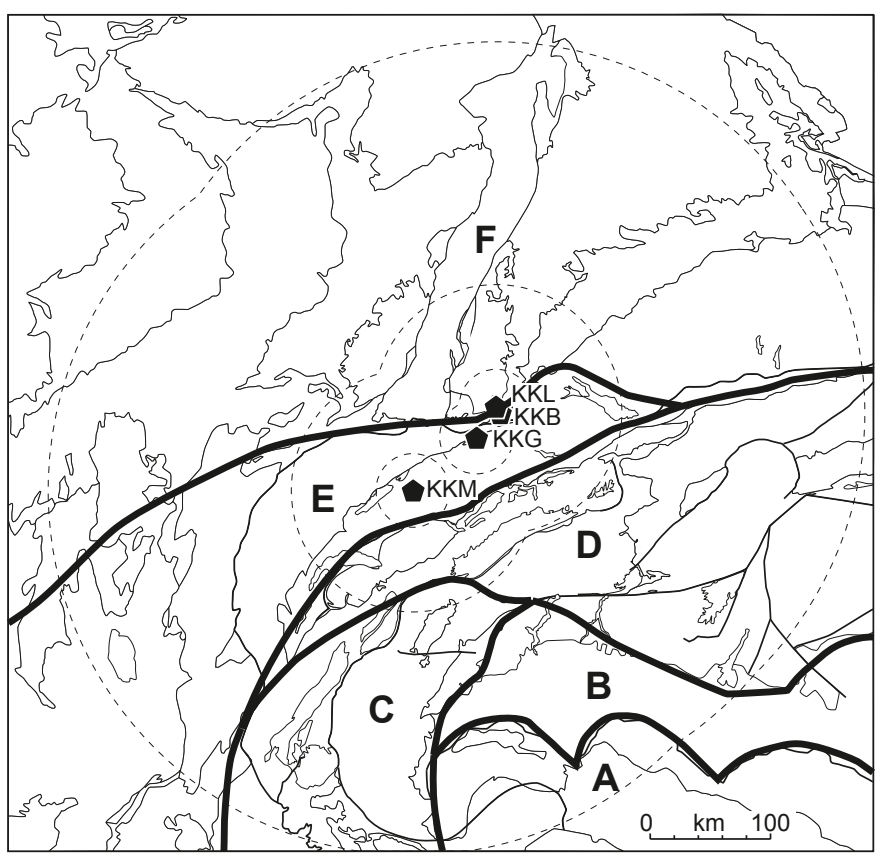

Fig. 5. Map of the Neotectonic Kinematic Provinces (NKPs) and location of the Swiss Nuclear Power Plants (KKL: Leibstadt; KKB: Beznau; KKG: Gösgen; KKM: Mühleberg; circles indicate the location of the 30-, 100- and 300-km radii around the power plants). The NKPs are A: Apennines; B: Adria Plate; C: Western Alps; D: Central and Eastern Alps; E: proximal Alpine foreland; F: distal Alpine foreland.

Western Alps). Its limits are characterised by young to recent deformations, which however are very distant from the area of interest (Meletti et al. 2000).

NKP B (Adria plate). This area acts as an indenter in respect to the European foreland (i.e. Schmid \& Kissling 2000) and is considered a rigid microplate which moved (and still moves) to the WNW relative to a fixed European framework, and which at the same time rotates counter-clockwise around a pole located in western Liguria (Meletti et al. 2000). To the east, mainly compressive movements are taken up in the Friuli area (just off the map of Fig. 5). This area extends westwards with a transpressive character along the boundary between NKPs B (Adria plate) and D (Central and Eastern Alps). Further to the west, this dextrally transpressive movement zone produces two deformation zones which were active in the recent geological past and which are, in parts, also active at the present time: (1) the Canavese line, located between NKPs B (Adria plate) and C (Western Alps), and (2) the Simplon-Rhone line (Schmid \& Kissling 2000), located between NKPs C (Western Alps) and D (Central and Eastern Alps). Eventually, this Simplon-Rhone line swings around into a N-S orientation, which leads to Wdirected thrusting of NKP C (the Western Alps) onto NKP E (Proximal Alpine Foreland). This thrusting is well documented along the Pennine Frontal Thrust, active during late Oligocene to Early Miocene times (Ceriani et al. 2001; Schmid \& Kissling 2000). However, since then deformation propagated further 
into the foreland (Fügenschuh \& Schmid 2003). The front of the Western Alps (NKP C) propagated further to the west and in front of the external massifs during younger (Late Miocene to Pliocene) geological periods. Its suspected present-day position (see position of NKP boundary between C and E) is largely mapped after Grellet et al. (1993).

NKP C (Western Alps). This part of the Alps was and still is at least partially displaced towards the WNW, together with the Adria plate. Thereby it absorbs part of the WNW directed translation of Adria with respect to Europe. Eastward the WNW directed translation of NKP C, in respect to NKP D, is taken up by the dextral Centovalli-Simplon-Rhone faults (Schmid \& Kissling 2000). The limit between NKPs C and D conveniently explains dextral strike-slip motion and the abrupt change of the stress regime along and across the Rhone valley, respectively (Maurer et al. 1997).

A kinematic link to the Friuli convergent zone (boundary between NKPs B and D) is likely, but the neotectonic evidence for such a direct link is weak.

NKP D (Central and Eastern Alps). The southern boundary is defined by the Valais-Simplon-Garda movement zone, which extends into the Friuli active area located just outside the SE edge of Fig. 5. The northern limit corresponds to the northern front of the Alps. This northern front of the Alps is characterised by two features. Firstly, it corresponds to the southern limit of the zone of deep crustal earthquakes characteristic for the European foreland (Provinces E and F; Deichmann 2002). Secondly, it corresponds to the northern limit of significant present-day thrusting activity (seismotectonic evidence provided by Deichmann et al. 2000; Kastrup et al. 2004). Towards the SW where NKP D wedges out, at least the second of the abovementioned characteristics is also valid for the limit between NKPs C and E. Here NKP C represents the front of the Western Alps.

NKP E (Proximal European Foreland). NKPs A and B are proposed to push onto the European foreland, according to the adopted kinematic model (Meletti et al. 2000). NKPs C and D ("Alps") are very strongly deformed by this ongoing collision while the European foreland (NKPs E and F) is less affected. The subdivision of the European foreland into NKPs E and F is guided by the concept that the Alpine front (in the sense of the northern limit of shortening within the basement) possibly migrated northward from its original position at the front of the Alps 13 Ma ago (thin-skinned Jura folding; i.e. Burkhard 1990; Burkhard \& Sommaruga 1998) into its present position at the front of the Jura in the Basel area. Of course this concept is only valid if deformation within NKP E is indeed characterized by a component of "thick-skinned" shortening. In any case, this boundary marks the northern limit of present-day tectonic activity (Müller et al. 2002; Ustaszewski \& Schmid 2007). The northern boundary of NKP E starts to branch off the front of NKP D near lake Constance and then follows the northern rim of the ENE-WSW-striking Permo-Carboniferous trough (Müller et al. 2002 and references cited therein). It also delimits a region of recent relative uplift of NKP E from a region of relative subsidence at the southern limit of NKP F within the NAGRA precision levelling network (Müller et al. 2002). Further to the WSW the limit was drawn along the Rhine-Bresse transform corridor and north of a small basement uplift (massif de la Serre), then across the northernmost part of the Bresse graben and finally into the northernmost Central Massif, mostly according to Grellet et al. (1993).

NKP F (Distal European Foreland). While NKP E is relatively strongly affected by deformation in the northern Alpine foreland, related to the indentation of the Adria plate (NKP B), this NKP F is characterised by weaker deformation, which does no more appear to be related to this indentation everywhere. Additionally, this region is affected by young volcanic activity. Many authors have invoked processes such as deep crustal and/ or mantle flow for this and for a multitude of other reasons (e.g. Laubscher 1992). This region is also characterised by strong recent uplift (parts of the Black Forest, Rheinisches Schiefergebirge) for which mantle up welling rather that a direct effect of compression in front of the Alps in terms of thrusting may be invoked. However, we propose that the stress field exerted by plate collision in the Alps is still felt within NKP F during Neogene to present times.

Within the Swiss territory the front of the Alps (boundary between NKPs D and E) was an important boundary in the geological past (e.g. Schmid et al. 1996). However, as pointed out above, the deformation front of the Central Alps possibly migrated further to the north from the Late Miocene onwards which led to the definition of another NKP boundary between NKPs E (Proximal Alpine Foreland) and F (Distal Alpine Foreland). More important in terms of seismicity is the fact that the front of the Alps, i.e. the northern margin of NKP D, represents a marked boundary regarding the focal depth distribution of present-day earthquakes. Furthermore, it also represents an important boundary regarding the seismotectonic regime (Deichmann 2002).

\section{Mapping seismogenic sources}

In addition to the general kinematic framework and concepts regarding the neotectonic activity in general the distribution of present-day seismicity, as based on the historical and instrumental catalogues, also needs to be taken into account when mapping seismogenic sources. A zone-less approach with spatial smoothing was seriously taken into consideration but finally rejected during our evaluation, primarily because the seismotectonic knowledge about the Alpine domain allowed us to adequately define a kinematic framework able to explain the present seismogenesis. It also turned out that, given distributed deformation along the extremely diffuse plate boundary between the Adria plate and the distal Alpine foreland, it was convenient to map seismogenic source areas referred to as seis-

128 S. M. Schmid \& D. Slejko 
mogenic zones. The only line sources we consider in addition to source areas are the so-called Reinach Fault (RF; Meghraoui et al. 2001) and the Fribourg Fault (FF; Kastrup et al. 2007).

Since the area of interest is not characterised by a still active subduction zone, and as the precision of focal depths does not allow for an appropriate 3-D-resolution, all the area source boundaries are taken as vertical and "hard", i.e. the position of zone boundaries is fixed. Given the results of a detailed seismotectonic analysis leading to alternative zonations in critical areas we feel no need for introducing "soft" boundaries. However, in a few cases and on the basis of specific seismological considerations, some epicentres will be attributed to a seismogenic zone that is adjacent to the one within which they are located in our map. Furthermore, when evaluating $b$-values, some seismogenic zones will have to be lumped together in order to gather sufficient information from the seismogenic zone earthquake catalogue. Such larger areas defined later and referred to as Macro-Zones (MZs), will be defined for a completeness analysis of the earthquake catalogue.

Generally, seismicity is taken to be homogeneous within all seismogenic zones. This procedure is justified since we define very small seismogenic zones whose size decreases when approaching the sites of the NPPs. No background zones are introduced because the entire map is subdivided into seismogenic zones.

Ruptures that are longer than the dimensions of a given seismogenic zone are allowed to extend beyond its boundaries. We do so because the geometry of the SZs is based on general seismotectonic considerations, and a precise calibration of their size is not done according to the maximum magnitude (Wells and Coppersmith 1994 relations). In any case, ruptures across zone boundaries can occur in the case of very large magnitude events only. Allowing earthquake ruptures to spread across boundaries allows for a very detailed zonation by the use of small seismogenic zones without making large ruptures a priori impossible.

\subsection{Mapping Seismotectonic Regions: a first step towards defining seismogenic zones}

The map of areas we refer to as Seismotectonic Regions (SRs) presented in Fig. 6 is constructed according to the following procedure: the boundaries drawn in the map of the NKPs (Fig. 5) are maintained, but a new set of boundaries now further subdivides them. The criteria for inserting these new boundaries are: (a) seismotectonic evidence (e.g. Sue et al.1999; Deichmann et al. 2000; Deichmann 2002; Kastrup et al. 2004), and (b) evidence for the existence of sets of pre-existing faults that are prone to reactivation and characterization of their pre-dominant orientations. Below we characterize the regions mapped in Fig. 6.

NKPs A and B remained un-subdivided and constitute SRs $\mathbf{A}$ and B. Their large distance to the area of interest does not warrant further subdivision. Most of NKP A is constituted by the Alps-Apennines transfer zones (Meletti et al. 2000) with expected sinistral strike-slip focal mechanisms in the shallow

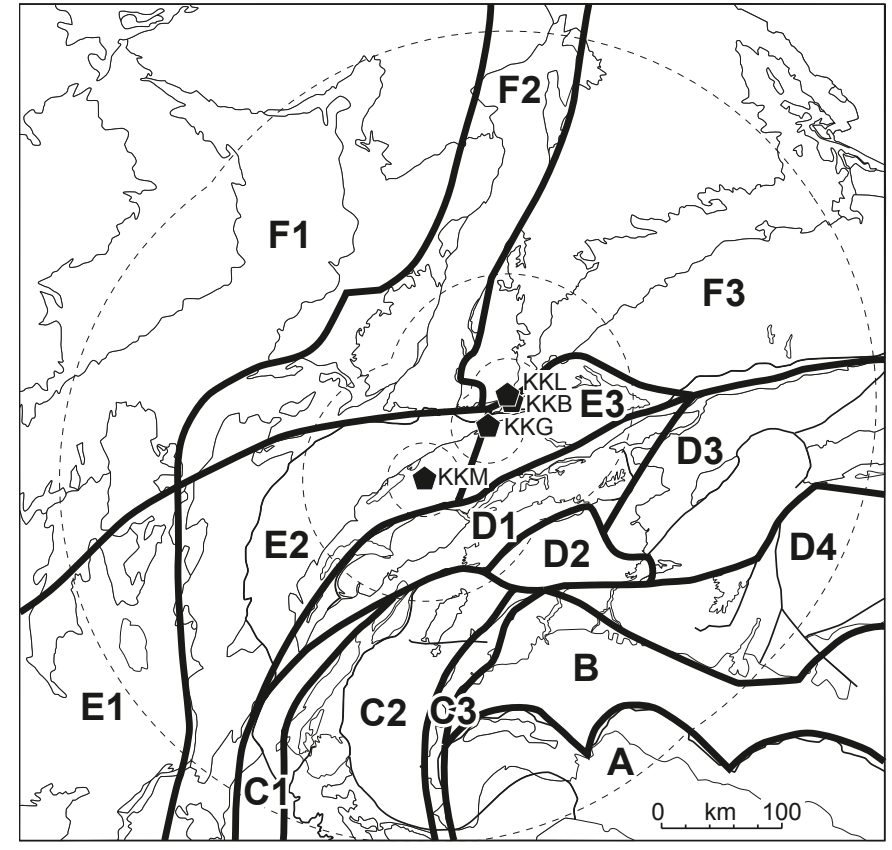

Fig. 6. Map of the Seismotectonic Regions (SRs) arrived at by further subdivision of the NKPs (consult also legend for Fig. 5). The SRs are A: Apennines; B: Adria Plate; C1: western compressional belt of Western Alps; C2: central extensional belt of Western Alps; C3: eastern compressional belt of Western Alps; D1: Northern Alpine compressional region; D2: Central Alpine dome; D3: Eastern Alpine extensional region; D4: Southern compressional region; E1: Massif Central; E2: Bresse - Jura - Western Molasse basin region; E3: Eastern Molasse basin; F1: Paris Basin; F2: Upper Rhine Graben; F3: Black Forest - Schwäbische Alb region.

crust and dip-slip mechanisms in the deep crust. NKP B comprises the Po plain and is considered as a relatively stable aseismic sector.

NKP C is further subdivided according to the work of Sue et al. (1999) and Eva et al. (1997) into: (1) western SR C1, presently subject to a compressional regime, (2) central SR C2, now in an extensional regime and (3) eastern SR C3, with a compressional regime. SRs $\mathrm{C} 1$ and $\mathrm{C} 3$ are characterised by strike-slip to thrusting fault plane solutions and absorb relative WNW-directed movements between NKPs A and B in respect to NKP E. SR C2, characterised by normal dip-slip fault plane solutions, is currently in extension due to gravitational forces ("over-thickened" crust). These gravitationally induced stresses dominate within SR C2, at least within the shallow crust.

NKP D is further subdivided into: (1) northern SR D1, with a compressional regime (strike-slip and subordinate thrusting), (2) central dome SR D2, (3) Austroalpine extensional SR D3 and (4) southern compressional SR D4 (no seismotectonic evidence). SR D1 is characterised by the present-day coexistence of all three types of focal mechanisms, including mostly shallow thrusting events. On the whole strike-slip motion and subordinate thrusting predominate. The southern limit of SR D1 is diffuse. The northern limit (D-E NKP boundary) is well defined 
and coincides with a change regarding the depth distribution of earthquake foci (Deichmann 2002). The area south of this D-E NKP boundary is characterised by the absence of earthquakes deeper than about $15 \mathrm{~km}$. North of this boundary earthquakes do occur all the way down to the Moho, $35 \%$ of them below $15 \mathrm{~km}$ and above the Moho. SR D2 is a quiet region, possibly due to the persistence of a thermal anomaly associated with the Tertiary (Lepontine) metamorphic dome. Hence the stress regime remains unknown. The outlines of SR D2 are drawn parallel to the isograds of Lepontine metamorphism. SR D3 (Austroalpine extensional region) is again a region where the far field stress field interferes with gravity forces (similar to SR C2) but extension is oblique (rather than orthogonal as in SR C2) to the strike of the Alpine orogen (Kastrup et al. 2004). The fault plane solutions point to the predominance of normal faulting with subordinate strike-slip motion. SR D4 (southern "compressional" region) represents the eastern continuation of the Friuli compressional realm onto our map. Note, however, that the very intense present-day deformation associated with the Friuli area stops near the SE border of our map. This SR D4 is interpreted as being characterised by a compressional stress regime based on geological arguments only.

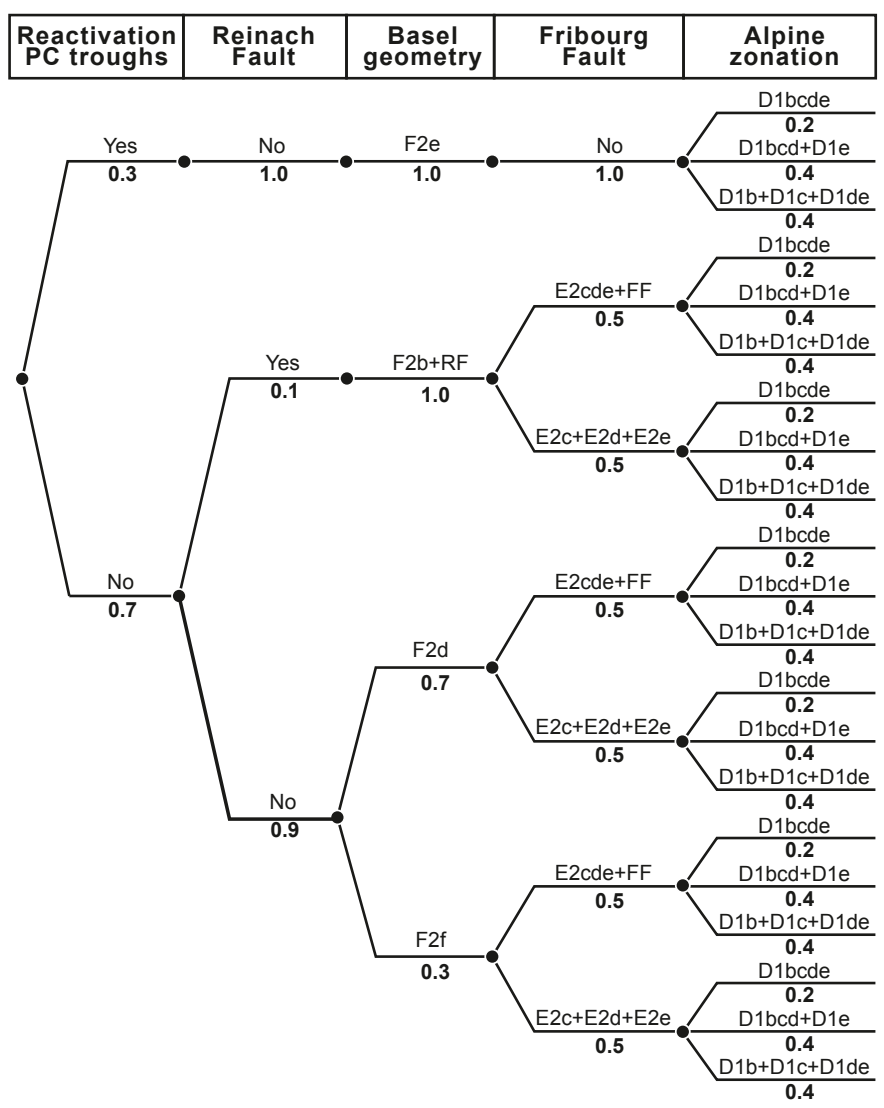

Fig. 7. Logic tree illustrating the definition of different groups of area sources (Seismogenic Zones; SZs) and line sources, including the weights attributed to the different branches.
NKPs $\mathrm{E}$ and $\mathrm{F}$ are further subdivided according to the predominance of certain sets of pre-existing faults into: 1) SR E1 Massif Central (reactivation mode unknown), 2) SR E2 BresseJura-Western Molasse basin (reactivated in strike-slip), 3) SR E3 Eastern Molasse basin (reactivated in strike-slip to normal fault motion), 4) SR F1 Paris basin (reactivated in strike-slip to normal fault mode), 5) SR F2 Rhine Graben region (reactivated in strike-slip mode), and 6) SR F3 Black Forest and Schwäbische Alb (reactivated in strike-slip to normal fault mode). SRs E1 and F1 were pre-fractured during the formation of the PC trough system in the Late Paleozoic. In these SRs this fault system predominantly strikes SW-NE (Grellet et al.1993); its orientation slightly departs from the WSW-ENE strike that predominates in northern Switzerland. No seismotectonic data, except for one normal fault plane solution (Grellet et al.1993), are available for SR E1 (Massif Central). The pre-existing faults in SR F1 (Paris basin) are presently reactivated in strike-slip to normal fault mode (Grellet et al. 1993). SRs E2 and F2 represent areas that are heavily affected by pre-existent faults that formed during Cenozoic Rhine and Bresse Graben formation; hence these SRs are pre-fractured by the Rhinish system as is evident from surface geology and from subsurface information (i.e. Meyer 1994b). This Rhinish system seems to form a very diffuse transform area occupying the entire western Molasse basin. The Fribourg Fault (FF) line source (Kastrup et al. 2007) lies within SR E2 and exhibits an almost perfect alignment of recent epicentres parallel to the Rhinish system. Both SRs E2 and F3 are characterised by strike-slip fault motions (Plenefisch \& Bonjer 1997; Kastrup et al. 2004). SRs E3 and F3, on the other hand, are dominated by the predominance of faults belonging to the Hercynic system, while those related to the Rhinish system are either absent or rare in these areas (e.g. according to subsurface data; Meyer 1994a; Birkhäuser et al. 2000; Marchant et al.2005). Seismotectonic evidence points to a predominance of strike-slip to normal faulting motions in SRs E3 and F3 (Plenefisch \& Bonjer 1997; Kastrup et al. 2004).

\subsection{Logic tree approach used for seismogenic zonation (Fig. 7)}

Consideration of the distribution of seismicity based on the historical and instrumental catalogues leads to an additional set of boundaries. These will define the Seismogenic Zones (SZs), a set of area sources characterized by uniform seismic properties within their limits. The boundaries of these SZs will largely, but not everywhere, follow the boundaries of the SRs (Fig. 6).

However, given all the uncertainties discussed earlier, alternative zonations have to be devised in parts of the area considered. The most important epistemic uncertainty relates to the role of the PC troughs, i.e. the question as to whether or not the PC troughs are presently reactivated by compression or transpression. This question is related to the thick-skinned vs. thin-skinned dilemma and the question as to which fault produced the strong Basel 1356 earthquake, as was discussed earlier.

130 S. M. Schmid \& D. Slejko 


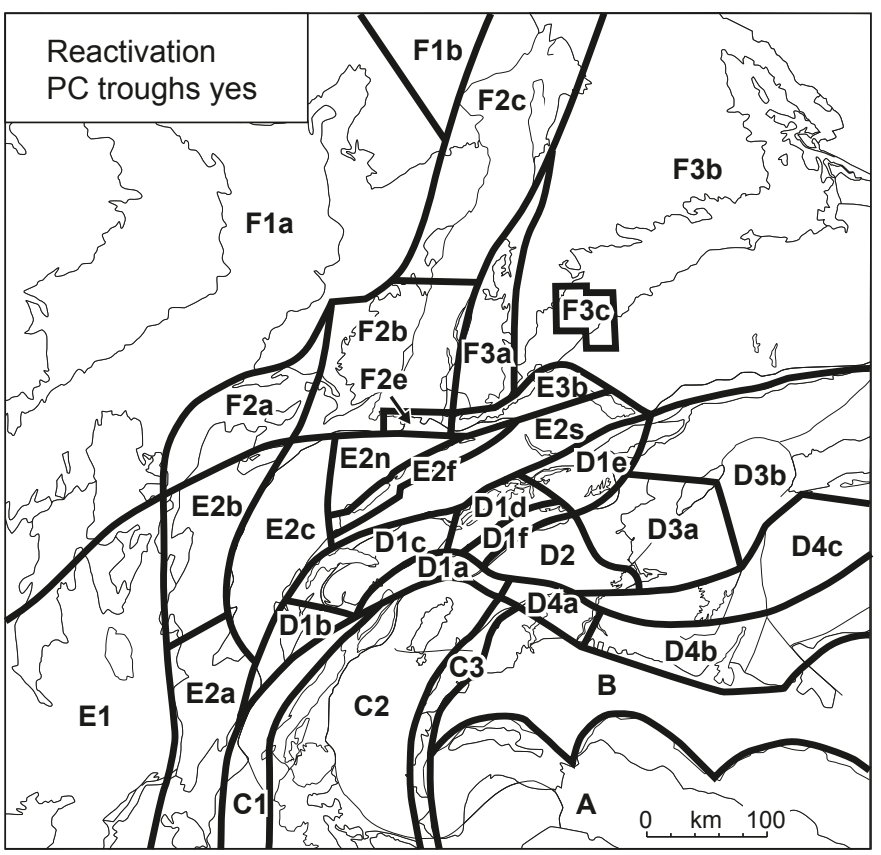

Fig. 8. Map of area sources, i.e. Seismogenic Zones (SZs: boundaries given by solid lines), assuming that the Permo-Carboniferous troughs are prone to seismogenic reactivation (Scenario "Reactivation PC troughs Yes" in Fig. 7). See text for abbreviations and further explanations.

Before discussing the individual SZs in more detail we will first evaluate the epistemic uncertainties expressed in the form of the logic tree depicted in Fig. 7. Note that one of the major difficulties during PSHA we encountered is that of assigning probabilities used as weights in the computations to bifurcations.

Node 1 (PC-Existence). This node considers the potential reactivation of the PC troughs. While most of the seismotectonic evidence argues against a reactivation of these structures, there is substantial geological evidence regarding their reactivation in thrusting mode during the geological past. The potential for thrust-mode reactivation in the future is given a probability of only 0.3 , because we decided to put more weight on the seismotectonic evidence, which might reflect the present and future tectonic activity better than the geological record. This first bifurcation leads to the two alternative source maps depicted in Figs. 8 and 9. Fig. 10 shows the seismogenic zonation of the Alpine foreland for the case that the PC troughs are considered as prone to seismogenic reactivation. Assuming that the PC troughs are not seismically active leads to a number of alternative zonations we propose for the Basel area (Fig. 11) and the Alpine foreland (Fig. 12), respectively.

Node 2 (RF). This bifurcation, that addresses epistemic uncertainties regarding the Reinach Fault line source as a potential

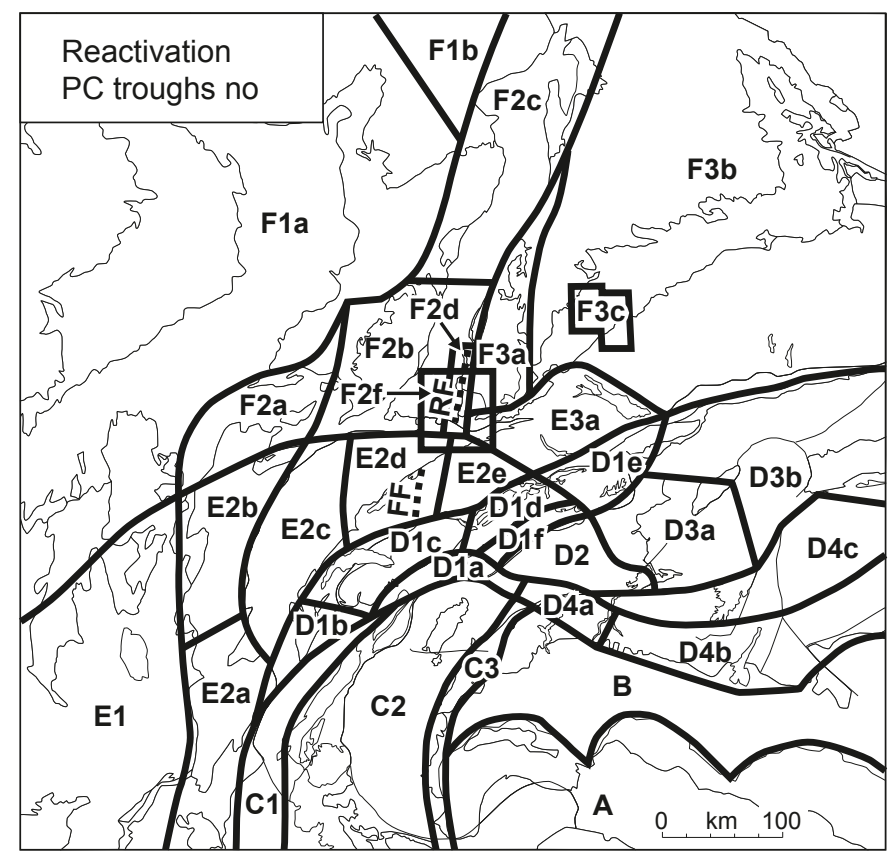

Fig. 9. Map of area sources, i.e. Seismogenic Zones (SZs: boundaries given by solid lines) and a few line sources (broken lines), assuming that the PermoCarboniferous troughs are not prone to seismogenic reactivation (Scenario "Reactivation PC troughs No" in Fig. 7). See text for abbreviations and further explanations.

source of Basel-type earthquakes ("RF yes" vs. "RF no" in Fig. 7), is only needed when assuming that the PC troughs are not prone to inversion in thrust mode (Fig. 9). This is because the RF, whose orientation is parallel to Rhinish system, cannot be considered a viable alternative for the case that the 1356 Basel earthquake is assumed to be associated with thrust-mode reactivation of the PC troughs. The low weight (0.1) given to the option "RF yes" reflects our scepticism regarding the evidence provided by Meghraoui et al. (2001) that the RF is indeed the seismogenic source of the 1356 Basel earthquake. Note that by choosing the combination "RF no" and scenario "Reactivation of PC troughs No " (Fig. 7) we in fact assign a probability of 0.7 to the likelihood that SZ F2d (Fig. 9) hosted the Basel earthquake. This is because we regard it more likely that the seismogenic fault linked to the Basel earthquake was parallel to the Rhinish system, oriented parallel to the long side of the rectangle defining SZ F2d (Fig. 9). However, we do not want to exclude the possibility that the Basel earthquake might have been triggered by an intersection effect between the Rhinish and PC trough fault systems, meeting and crossing each other in the Basel area (weight of 0.3 given to square-shaped area F2f, also see Fig. 9), nor do we exclude thrust mode reactivation of the PC troughs (Node 1, branch reactivation PC troughs yes in Fig. 7).

Node 3 (Basel geometry). Because the fault associated with the 1356 Basel historical earthquake remains unknown we in- 


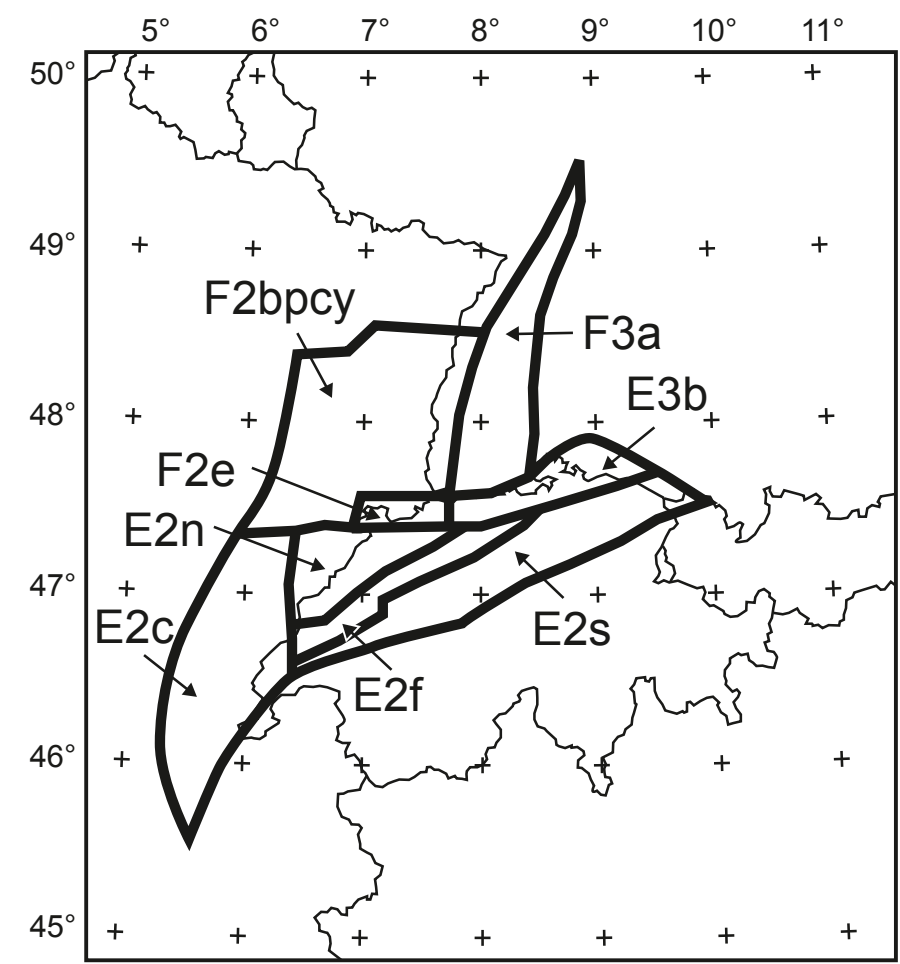

Fig. 10. SZs in the Alpine foreland assuming that the Permo-Carboniferous troughs are prone to seismogenic reactivation (Scenario "Reactivation PC troughs Yes" in Fig. 7).

troduce a series of alternative zonations for the Basel area. In case of the scenario "Reactivation of PC troughs Yes" no further bifurcation is needed and SZ F2e is chosen for the Basel area (Fig. 8). Thereby it is implicitly assumed that the $1356 \mathrm{Basel}$ earthquake reactivated the $\mathrm{PC}$ troughs somewhere within area F2e. Furthermore, the RF is not considered to be a localizer of seismicity, and the Basel source is represented by the eastwest trending SZ F2e (Fig. 8). For the scenario "Reactivation of PC troughs No" (Fig. 9) two alternatives are proposed. If RF is considered a line source, it comes to lie within a larger zone (source area F2b_RF, Fig. 11a). If not, the Basel region is modelled as a narrow, north-south trending zone (F2d; Fig. 11b), or as a large zone representing the intersection of north-south and east-west structures (F2f; Fig. 11c). When using SZ F2f the surrounding zones are modified (e.g. zone F3a changes to zone F3a_F2f; Fig. 11c).

Node 4 (Fribourg Fault FF). While activity along the Fribourg Fault (FF) is well documented by post-1975 instrumental data (Kastrup et al. 2007) there remains an epistemic uncertainty as to whether an introduction of this line source is needed or not. Hence a bifurcation was applied to all branches that assume scenario "Reactivation of PC troughs No". The node 4 bifurcations were assigned equal $(0.5)$ probabilities because we could not decide as to which branch might be more likely. Either FF is not treated as a line source and areas E2c, E2d and E2e are treated as separate SZs (see Figs. 12a \& b), or alternatively, FF represents an important line source within a larger source area consisting of E2c, E2d and E2e, lumped together to area E2cde (see Figs. 12c \& d).

Node 5 (Alpine zonation). The alternatives regarding SZs D1b, D1c, D1d and D1e depicted in Fig. 13 are treated with 3 branches in the logic tree (Fig. 7) as follows: Branch 1: D1b, D1c, D1d, and D1e are grouped into 1 SZ (D1bcde; Fig. 13a); this branch is weighted 0.2. Branch 2: D1b, D1c, and D1d are grouped into $1 \mathrm{SZ}$ (D1bcd), which is separated from D1e (Fig. 13b); this branch is weighted 0.4. Branch 3: D1d and D1e are grouped into one SZ (D1de), which is separated from D1b and D1c (Fig. 13c); this branch is weighted 0.4. These alternatives are independent of all previously mentioned alternatives and they were applied to every previously defined branch of the logic tree.

\subsection{Definition and characterization of Seismogenic Zones}

We now discuss details concerning the mapping of the SZs shown in Figs. 8 to 13. Note that the exact location of these limits is crucial in the neighbourhood of the NPPs, since area sources are characterized by uniform seismic properties all the way to their limits. The boundaries of the SZs will largely, but not everywhere, follow the boundaries of the SRs (Fig. 6).

3.3.1. Seismogenic Zones within the Neotectonic-Kinematic Provinces A, B, and C

The NKPs A and B (Fig. 5) remain undivided since they are too distant from the NPP sites to warrant further subdivision. They correspond to SZ A (Apennines) and SZ B (Adria plate), respectively. No assumptions are proposed concerning orientation of faults and type of faulting within SZ A. SZ B is almost aseismic.

Also seismotectonic region SR C1 (Fig. 6) remains undivided and represents SZ C1 (western compressional belt of Western Alps). No a-priori orientation of active faults is assumed; expected sense of slip is strike-slip to thrusting. SR C2, not subdivided either, is identical with SZ C2 (central extensional belt of Western Alps). There the orientation of active faults is assumed to be orogen-parallel, i.e. N-S to NE-SW, expected sense of slip is normal faulting. SR C3, also not subdivided, represents $\mathbf{S Z}$ C3 (eastern compressional belt of Western Alps). No a-priori orientation of active faults is assumed; expected sense of slip is strike-slip to thrusting.

\subsubsection{Seismogenic Zones within the Neotectonic-Kinematic} Province D

The D1-D3 boundary as shown in Fig. 6, i.e. the map of the SRs, had to be slightly modified according to seismicity criteria. The boundaries between NKPs D and E, as well as those

132 S. M. Schmid \& D. Slejko 

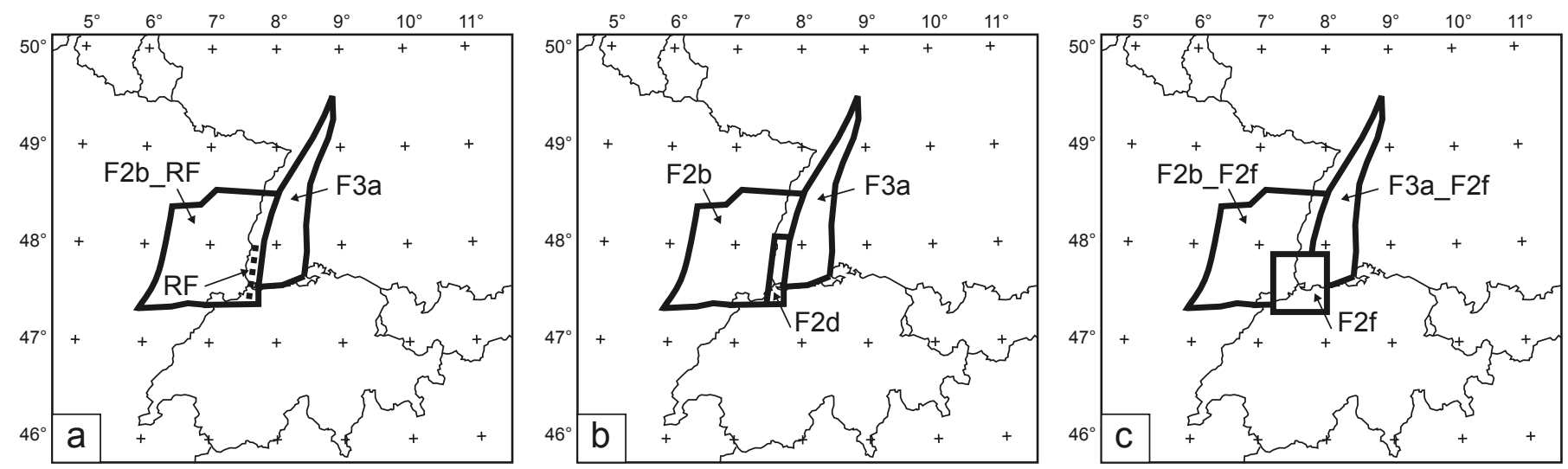

Fig. 11. Alternative SZs for Basel area assuming that the Permo-Carboniferous troughs are not prone to seismogenic reactivation (Scenario "Reactivation PC troughs No" in Fig. 7), see text for further explanations.

between NKPs C and B also had to be slightly modified. Changes to these major boundaries are made taking into account the following considerations: 1) near Lake Geneva the northern boundary of NKP D with $\mathrm{E}$ is moved away from the front of the Alps by a small distance into the Molasse basin in order to capture badly located epicentres around Geneva within NKP D (instead of E);2) the discrete southern bound- ary of NKP D with C and B (Valais-Simplon-Garda movement zone) is replaced by a series of elongated SZs (D1a, D4a, and D4b). Particularly SZ D4a overrules former boundaries drawn in Fig. 6. The SZs within the SR D1, as depicted in Figs. 8 \& 9 (see also Fig. 13 for alternative SZs in the Alpine foreland previously discussed in the context of node 5 of the logic tree of Fig. 7), are characterized as follows:
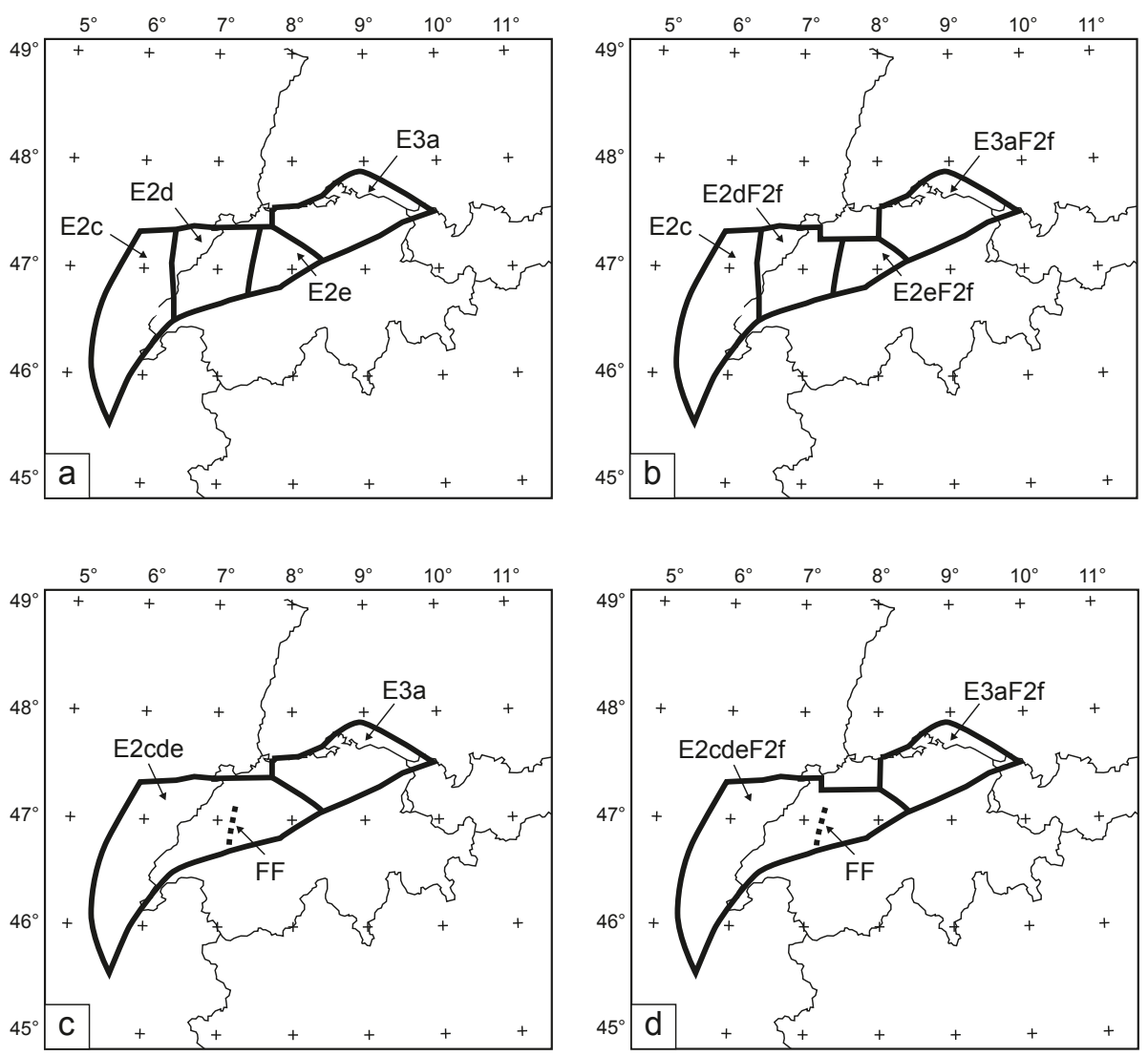

Fig. 12. Alternative SZs in the Alpine foreland assuming that the Permo-Carboniferous troughs are not prone to seismogenic reactivation (scenario "Reactivation PC troughs No" in Fig. 7); see text for further explanations. 

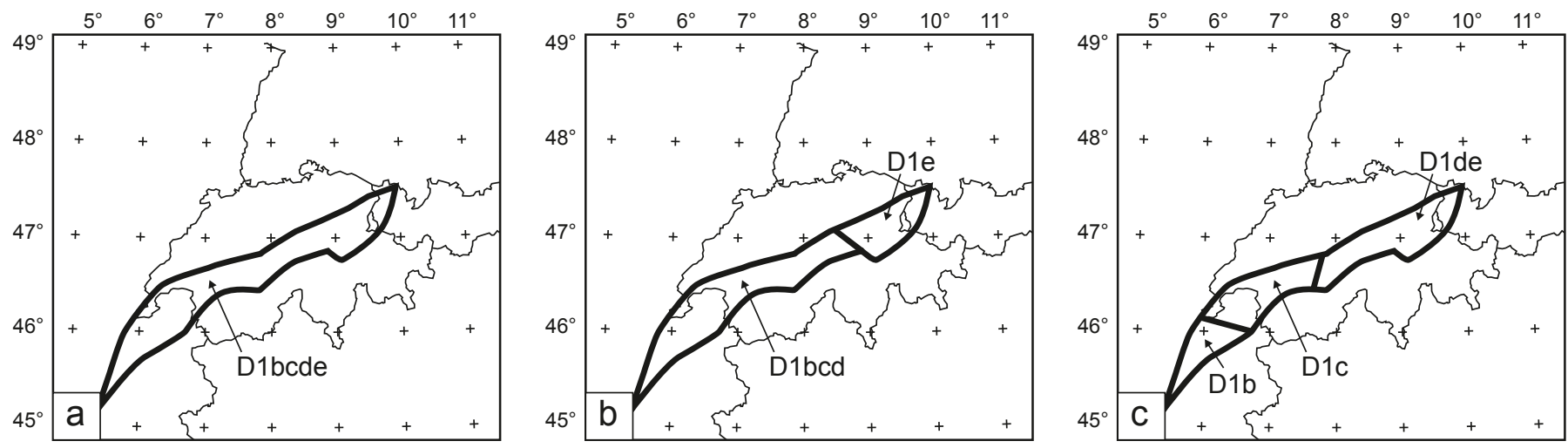

Fig. 13. Alternative SZs for the Northern Alpine compressional region, see text for further explanations.

SZ D1a (westernmost part of the Valais-Simplon-Garda movement zone) is an E-W trending belt of enhanced seismicity, including the northern part of the Valais active area, located within the southernmost Helvetic nappes. Fault-orientation is roughly E-W and parallel to the elongated shape of the area. Sense of slip is predominantly dextral strike-slip.

SZ D1b (Savoy part of northern margin of the Alps) is located in an area were Alps and Jura meet. This SZ is transitional to SZ C1 (external part of Western Alps) and is relatively quiescent compared to the more active SZ D1c. No a-priori fault orientation is assumed and sense of slip is strike-slip with subordinate thrusting.

SZ D1c (western Switzerland part of northern margin of the Alps) is characterized by a relatively high density of epicentres. The boundary of this SZ appears transitional with SZ D1a (northern part of Valais active zone). No a-priori fault orientation is assumed and dominant sense of slip is strike-slip with subordinate thrusting or normal faulting.

SZ D1d (central Switzerland part of northern margin of the Alps) includes the seismically very active area around Lake Lucerne, mostly inferred from historical information. Historical record probably includes thrusting quakes. No a-priori fault orientation is assumed and dominant sense of slip is strike-slip, with subordinate thrusting.

SZ D1e (eastern Switzerland part of northern margin of the Alps) represents a part of the northern margin of the Alps, which might be kinematically linked via SZs E3a and E3b (eastern Molasse basin) to the northward propagation of foreland deformation across the Molasse basin, causing increasing amounts of recent uplift in the area west of Lake Constance (Müller et al. 2002). No a-priori fault orientation is assumed; dominant sense of slip is strike-slip (with subordinate thrusting).

SZ D1f (Aar massif) is a quiescent zone. No assumptions are made regarding fault orientation and/or sense of slip.

SR D2 remains undivided and corresponds to SZ D2 (Central dome), a quiescent zone, which is adjacent to D1f and cor- responds to the Lepontine metamorphic dome. No assumptions regarding fault orientation and/or sense of slip are made.

SR D3 is subdivided into two SZs. SZ D3a (Mittelbünden Engadin - northern Valtellina area) exhibits enhanced seismicity, with predominantly normal faulting and subordinate strikeslip. No assumptions are made regarding fault orientation. SZ D3b (western Austria) is generally characterized by moderate seismicity, but includes quite active areas such as the Inntal line. Hence, seismicity appears unequally distributed, but given its relatively large distance from the NPPs this SZ is nevertheless considered homogeneous. Fault orientation is ENE-WSW and sense of slip is sinistral strike-slip.

Three SZs are defined within the SR D4.

SZ D4a (Insubric part of Valais-Simplon-Garda movement zone) is a relatively quiet part of a longer and important movement zone. No assumptions can be made regarding fault orientation and sense of slip.

SZ D4b (Southern Alps part of Valais-Simplon-Garda movement zone) is relatively active and directly connects with the Friuli area, located immediately east of the margin of the map. There is good agreement between the outlines of our map with those provided by with the data of Meletti et al. (2000). Reverse faults strike $\mathrm{N} 70^{\circ} \mathrm{E}$.

SZ D4c (Trento area) is a relatively quiescent block. No assumptions can be made regarding fault orientation and sense of slip.

\subsubsection{Seismogenic Zones within the Neotectonic-Kinematic}

Province E

The two alternative zonations proposed in Figs. 8 \& 9 largely deal with alternative subdivisions of this province. The E2-E3 boundary (Fig. 6) between the eastern and western parts of the Molasse basin is modified and only kept in one of the two options for seismogenic zonation, namely that depicted in Fig. 9. Moreover, the boundary between the SRs E2 and F2 (Fig. 6) has to be modified in the Basel area in order to properly take

134 S. M. Schmid \& D. Slejko 
account of the specific needs of the Basel source area (see Figs. $8 \& 9)$.

No further subdivision is necessary within SR E1 in view of the large distance to the power plants. In SZ E1 (Massif Central) no assumptions are made regarding fault orientation and sense of slip.

SR E2, however, is subdivided into various SZs as follows.

SZ E2a (Basse Dauphinée) is characterized by a relatively higher seismic activity, when compared to E2b. Fault-orientation is that of the Rhinish system, sense of slip is strike-slip.

SZ E2b (Bresse) is a relatively quiescent area. Fault-orientation is that of the Rhinish system, sense of slip is sinistral strike-slip.

SZ E2c (Western Jura) is a relatively quiescent area, when compared to E2d. Fault-orientation is that of the Rhinish system, predominant sense of slip is sinistral strike-slip.

The following series of SZs are only activated when the scenario "reactivation PC troughs Yes" of Fig. 7 is assumed:

SZ E2d (Western Molasse basin), only defined in Fig. 9, is heavily pre-fractured by Rhinish faults, of which line source FF (located within this area) is a particularly active example. Prefracturing also occurred by the PC trough system, particularly near the Molasse-Jura border. Fault orientation is NNE-SSW and sense of slip is sinistral strike-slip. Line source FF, located within E2d, also is only defined for the scenario "reactivation PC troughs No" of Fig. 7 (see Fig. 9), and furthermore it only represents an alternative in one of the FF nodes (Fig. 7). Documented offsets of the base of the Mesozoic strata coincide with line source FF (see Meyer 1994b; Kastrup et al. 2007). They represent a good example for thick-skinned reactivation of former faults by sinistral strike-slip parallel the Rhinish system with a transpressive component (see Kastrup et al. 2007 for geological and seismotectonic evidence). Inversion of the PC trough system below the Molasse basin by thrusting (geological evidence is available from seismic sections only) is envisaged when assuming the scenario "reactivation PC troughs Yes" in Fig. 7 to be valid (see Fig. 8); in this case line source FF is de-activated.

SZ E2e (Central Molasse basin), a relatively quiescent area (Fig. 9), also is only defined within the scenario "Reactivation PC troughs No" of Fig. 7. This SZ is located east of the E2E3 boundary as defined in Fig. 6, coinciding with the eastern limit of existence of the Rhinish system. Some epicentres necessitate a very slight correction of this boundary. No assumptions can be made regarding fault orientation and sense of slip within this SZ.

Also SZ E3a (eastern Molasse, see Fig. 9) is only defined within scenario "reactivation PC troughs No" of Fig. 7 and, hence, when present-day tectonic activity is assumed to be primarily thin-skinned. This area is characterised by recent uplift and represents a neotectonically active zone according to Müller et al. (2002). In comparison to E2e this is a zone of increased seismicity. The SZ is pre-fractured by the Hercynic and PC trough systems, particularly at its northern margin. Within the basement, sense of slip is expected to be a combination of dextral strike-slip and normal faulting, primarily reactivating the Hercynic system.

The following series of SZs are only activated when the scenario "reactivation PC troughs Yes" of Fig. 7 is assumed, hence when assuming that the $\mathrm{PC}$ trough is presently reactivated. This scenario proposes inversion of normal faults by thrusting or transpression. It also infers that the Basel earthquake corresponds to such an inversion of a PC trough in the Basel area (see description of SZ F2e). These SZs span the SRs E2 and E3 of Fig. 6 (western and eastern Molasse basin) and are the following (see Fig. 8):

SZ E2n (eastern Jura) is located between the northern PC trough (SZs F2e and E3b) and the southern PC trough (SZ E2f). It is pre-fractured by the Rhinish system; the expected sense of slip is sinistral strike-slip.

SZ E2f (southern PC trough) corresponds to the southern PC trough, joining the northern one in the NE (boundary with SZ E3b) according to the available subsurface data. This SZ is pre-fractured by ENE-WSW-striking normal faults, which are supposed to be presently reactivated by thrusting. The area is also pre-fractured by the Rhinish system and reactivated in sinistral strike-slip mode.

SZ E2s (southern Molasse basin) encompasses the rest of the Molasse Basin located south of SZ E2f. The area is pre-fractured by the Rhinish, Hercynic, and PC trough systems. Sense of slip is expected to be sinistral strike-slip (Rhinish system), a combination of dextral strike-slip and normal faulting (Hercynic system) and minor thrusting (PC trough system).

SZ E3b (eastern part of northern PC through) is an elongated strip. It contains the eastern part of the northern PC trough, linking to Basel SZ F2e (western part of northern PC). Inversion of the PC trough system by thrusting is expected, possibly in the form of characteristic earthquakes implying that each fault generates earthquakes of a well-defined magnitude only (Schwartz \& Coppersmith 1984). However, the expected recurrence rate is lower than that expected for SZ F2e (Basel area). In addition, the Hercynic system is also expected to be reactivated by a combination of sinistral strikeslip motion and extension (e.g. "Neuhausener Störung", an extremely well studied area; Birkhäuser et al. 2000; Marchant et al. 2005).

\subsubsection{Seismogenic Zones within Neotectonic-Kinematic Province $F$}

The Basel area, and particularly the Basel 1356 earthquake, plays a key role within NKP F. In order to properly account for the seismicity in the Basel area the boundary between NPK F and NKP E (Fig. 5) is modified, as well as that between the SRs F2 and F3 (Fig. 6). Several alternatives are considered for the Basel area.

Two SZs are defined within SR F1 (Fig. 8). SZ F1a (Paris basin) includes most of SR F1 and is characterised by very moderate seismicity. The orientation of faults is variable; strikeslip to normal fault modes predominate. SZ F1b (Lower Rhine 
Graben area) contains pre-existing fault sets which are mostly NW-SE-oriented (Lower Rhine Graben, extending into the Netherlands), but also fault sets which are NE-SW-oriented. Sense of slip is strike-slip to normal faulting.

A substantial number of SZs is defined within SR F2. Two SZs are defined within the Rhine-Bresse transform area. SZ F2a (western part of Bresse-Rhine transfer area) is seismically less active (as compared to F2b). It was pre-fractured by the Rhinish system (NE-SW-oriented in this area); sense of slip is strike-slip with subordinate normal faulting. SZ F2b (eastern part of Bresse-Rhine transfer area is seismically more active and immediately adjacent to a series of alternatives concerning the zonation of the Basel area, i.e. adjacent to SZs F2d, F2e, F2f, and line source RF. The zone is primarily pre-fractured by the Rhinish system (NNE-SSW-strike); its reactivation is by strikeslip to normal faulting. However, thrusting by reactivation of the PC trough system also occurs (i.e. Rigney earthquake near Besançon of the 23. 2. 2004; Baer et al. 2005). Subordinate normal faulting occurs along the Hercynic system. The exact size of this area depends on the choices regarding the first 3 bifurcations in the logic tree (Fig. 7), as is depicted in Figs. 10 and 11. F2bpcy (see Fig. 10) denotes the size of F2b when assuming scenario "Reactivation PC troughs Yes". In the case scenario "Reactivation PC troughs No" is preferred (see Fig. 11) F2b_RF defines its size when being considered to contain the $\mathrm{RF}$ line source. F2b without a suffix is used if $\mathrm{F} 2 \mathrm{~d}$ is chosen in the Basel area; F2b_F2f denotes its size when, alternatively, F2f is chosen.

In the area of the Upper Rhine Graben we define SZ F2c (Upper Rhine Graben) as a less active part of the graben (Figs. 8 \& 9), pre-fractured by the Rhinish as well as the Hercynic fault systems. Expected sense of slip is strike-slip. Normal faulting reactivating the Hercynic system is also expected.

In the Basel area several alternatives entering the logic tree (Fig. 7) are defined. If the Reinach fault (RF) is indeed the surface expression of the seismogenic fault associated with the 1356 earthquake, it has to be treated as a very important line source (line source RF); it would have originated the Basel earthquake and could potentially originate events with very high magnitude in the future (see RF-bifurcation in the logic tree of Fig. 7). However, since we regard it as rather unlikely that the RF is a seismogenic feature, we define three alternative SZs (F2d, F2e and F2f), which are chosen large enough in order to include a potentially seismogenic fault which is long enough for accommodating the Basel 1356 earthquake, whatever its exact orientation and location might have been. Line source RF (Fig. 9) assumes that past and future quakes, similar to the 1356 Basel earthquake, all took and will take place along the seismogenic RF. Sense of slip is sinistrally oblique normal faulting. SZ F2d (Basel quake reactivates the Rhinish system, Fig. 9) assumes that past and future quakes, similar to the $1356 \mathrm{Basel}$ earthquake, took and will take place near to and parallel to the RF (Rhinish system, NNE-SSW-strike). Sense of slip is sinistrally oblique normal faulting. SZ F2e (western part of northern PC trough,
Fig. 8) assumes that past and future quakes, similar to the 1356 Basel earthquake, took and will take place along faults, which have the orientation of the PC trough (westward extension of E3a, but more seismogenic than E3a). Fault orientation is E-W; sense of slip is dextrally oblique thrusting. SZ F2f (Basel quake due to interference effects between the Rhinish and PC trough systems, see Fig. 9) does not make any a priori assumption about the orientation of the faults responsible for past and future quakes similar to the 1356 Basel earthquake. However, this alternative assumes that strong earthquakes will concentrate in an area around Basel where the Rhinish and PC trough systems intersect, whereby activity on the Hercynic system is also expected. Expected sense of slip is sinistrally oblique strike-slip to normal fault motion (Rhinish system), dextral oblique strike-slip to normal fault motion (Hercynic system) or oblique thrusting (PC trough system).

SR F3 is subdivided into 3 SZs. SZ F3a (eastern flank of Upper Rhine Graben, Figs. 8 \& 9) is an area of relatively high seismicity within SR F3, with a predominance of Rhinish and Hercynic faults. Sinistral transtension is expected on the Rhinish system, normal faulting on the Hercynic system. Note that the size of this area is altered when area F2 $\mathrm{f}$ is chosen for the Basel source geometry (and will be denoted area F3a_F2f in that case, see Fig. 10). SZ F3b (SW Germany, Figs. 8 \& 9) constitutes the largest part of SR F3. It is characterised by low seismicity, with a predominance of Rhinish normal faulting. SZ F3c (Schwäbische Alb) contains the enigmatic and seismically active Hohenzollern area. This area is characterised by intersections between the Rhinish and Hercynic systems; hence seismicity could be due to this intersection. In this case sinistral transtension on the Rhinish system and normal faulting on the Hercynic system would be expected. Present-day activity is sinistral strike-slip parallel to the Rhinish system, but this presently active source may not be stationary in time and space. Alternatively, the earthquakes in this area could also be due to magmatic processes (mantle up welling). In view of all these uncertainties no assumptions regarding fault orientation and/or sense of slip are made.

\subsection{Earthquake rupture geometry}

Epicentres are assumed to be uniformly distributed within source areas. Moreover, they are considered to define the midpoints of the rupture areas projected to the earth's surface. In case of epicentres located closer than half of the expected rupture length from the source zone boundary, ruptures are allowed to extend beyond the source boundary. Three specific styles of faulting are considered: normal, strike-slip and reverse. For each style of faulting, there is a preferred fault dip that should be used for modelling ruptures.

The depth distribution of earthquakes for the sources is defined by the following three distributions. For the northern Alpine foreland the depth distribution is triangular over the depth range 1 to $30 \mathrm{~km}$, with a peak at $10 \mathrm{~km}$ depth. For the

136 S. M. Schmid \& D. Slejko 
southern Alpine foreland and southern Germany sources the depth distribution is triangular over the depth range of 1 to $25 \mathrm{~km}$, with the peak again at a depth of $10 \mathrm{~km}$. For the remaining zones, the distribution is trapezoidal over the depth range of 1 to $20 \mathrm{~km}$, with the upper uniform region extending over the depth range of 1 to $10 \mathrm{~km}$. Earthquakes with sufficiently large fault planes are allowed to rupture the surface: this applies in particular to RF and FF.

\section{Earthquake recurrence relationships}

No data on strain rate and slip rate are available within the area of interest. Strain rates, as expected from the estimations of plate convergence rates based on geological reconstructions and plate tectonic constraints, are very low (Tesauro et al.2005). As a consequence, no unequivocal GPS data are available yet. Also, it is not known how displacements and/or strains are partitioned within the area of investigation.

A limited amount of data is available from paleoseismological investigations (Swiss Seismological Service 2002; Becker et al. 2005). Regarding the Basel area, a combination of investigations based on trench data, paleothems, lake deposits and rock falls suggests that 6 events between magnitudes 6 and 7 have occurred within the last $12^{\prime} 000$ years. The trench data provide the most complete set of events. The estimates of the magnitudes attributed to these events are questionable, however, since we believe that the RF represents an earthquake triggered landslide rather than an active fault scarp. The evidence provided by the colluvial wedges associated with these landslides, however, indicates a periodicity of events, which are likely to have been induced by earthquakes, regardless of the interpretation of the features seen in the trench (gravitational slide induced by seismic event vs. active fault scarp). Three out of the six events can be correlated with the data obtained by other methods in the area. In summary, it is likely that 3-6 strong events did occur within the last 12'000 years (Becker et al. 2005). These strong or "Basel-type" earthquakes are estimated to have a magnitude between 6 and 7. Taking a time span of 12'000 years and 6 events (the maximum number detected by paleoseismic work in order to be on the save side) a recurrence rate of 2000 years is calculated for the magnitude 6-7 range. In the sense that some strong events may have remained undetected, 6 events in 12 '000 years may or may not represent a minimum recurrence rate. In any case, this estimate is taken as the most realistic one and will be used in order to constrain the information gathered from the earthquake catalogue, where only one event of similar size is reported (the first record in the catalogue is dated 250 A.D.).

Paleoseismological data are also available from lake research in central Switzerland (Swiss Seismological Service 2002; Monecke at al. 2006; Schnellmann et al. 2006). However, no estimates of magnitude are available for these data at this stage. Hence, the data cannot yet provide additional constraints in comparison to the magnitude-frequency relationships deduced from the earthquake catalogue.

\subsection{Preliminary processing}

The earthquake catalogue used for this study is the Swiss catalogue (Fäh et al. 2003), referred to as ECOS. It lists 12'426 events, which occurred between 250 A.D. and 2000. Each event has been classified according to certainty and type. The catalogue was searched for questionable or fake events such as induced events, explosions and events of unknown type. Based on the results obtained, all the dubious events (989 in total) were eliminated from the catalogue that was finally used for further elaborations.

\subsubsection{Catalogue de-clustering}

The probabilistic approach for hazard computation chosen for project PEGASOS is referred to as seismotectonic probabilism (Muir-Wood 1993). Thereby the seismic process is considered Poissonian; consequently only main events are considered. There is no single best way for de-clustering earthquake catalogues. Preliminary de-clustering of the ECOS catalogue according to the methods of Gardner \& Knopoff (1974) \& Reasenberg (1985) demonstrated, that the difference between the various methods does not influence the computation of rates of seismicity in a significant manner. In fact the number of main events computed was 11'897 and 12'327 after applying the Gardner \& Knopoff (1974) and the Reasenberg (1985) declustering, respectively.

The performance of the two de-clustering schemes cited above was examined also by de-clustering a few well-known earthquake sequences (Sierre 1946, Sarnen 1964, Fribourg 1987-1999, Bormio 1999-2000). More precisely, the Gardner \& Knopoff (1974) method was tested considering three different parameterisations: the original parameters (Gardner \& Knopoff 1974), those for central Europe (Grünthal 1985), and those for California (Uhrhammer 1986). It was mainly investigated as to how the proposed schemes deal with sequences (either aftershocks or swarms) that contain several strong events, each having their own aftershocks. The best result was obtained by the Gardner \& Knopoff (1974) algorithm with the parameters suggested by Grünthal (1985). Consequently, this method is used for obtaining the final catalogue of 10'123 independent events used for PSHA.

\subsubsection{Catalogue completeness}

One of the prerequisites for the evaluation of recurrence relationships based on earthquake catalogues is that the analysis is restricted to regions, time periods and ranges of magnitudes for which the catalogue is complete. Hence the seismicity parameters $a$ and $b$ entering PSHA should in principle be defined separately for each source area (such as the SZs of Figs. 8 \& 9). A first parameter is related to the seismicity rate (annual number of earthquakes, proportional to the $a$-value) equal to, or larger than, a chosen magnitude class. The $b$-values establish the slope in the Gutenberg-Richter law (expressing the rela- 
tionship between the magnitude and annual cumulative number of earthquakes in any given region, as well as the maximum earthquake magnitude $\left.M_{\max }\right)$.

However, given the small size of some of the SZs, and hence, the scarce number of data within many of them, separate evaluations of catalogue completeness within each SZ turned out to be impossible. Moreover, such a procedure would be meaningless, because a given completeness is expected to only hold for larger regions that are characterized by similar methods of data collection, i.e. areas that cover several SZs.

For these reasons, we define larger areas for completeness analysis, areas we refer to as Macro-Zones (MZs). Light differences in the seismic behaviour are considered marginal with respect to the need for a larger number of earthquakes. These large MZs depicted in Fig. 14 are obtained by merging some SRs (Fig. 6). The three SRs C1, C2, and C3 are merged into a single MZ (MZ C); SRs D2 and D3 are grouped together to form MZ D2-3, while SRs E2 and E3 constitute MZ E2-3. Furthermore, limited changes are introduced regarding the borders of a few SRs (compare Figs. 6 \& 14) in order to guarantee seismotectonic homogeneity.

Since ECOS was assembled from a fusion of several different national catalogues (Switzerland, Italy, Austria, Germany, and France), the completeness information based on the documentation supplied with the individual national catalogues was compiled in a first step; subsequently the analysis considered the completeness of catalogue subsets corresponding to the MZs.

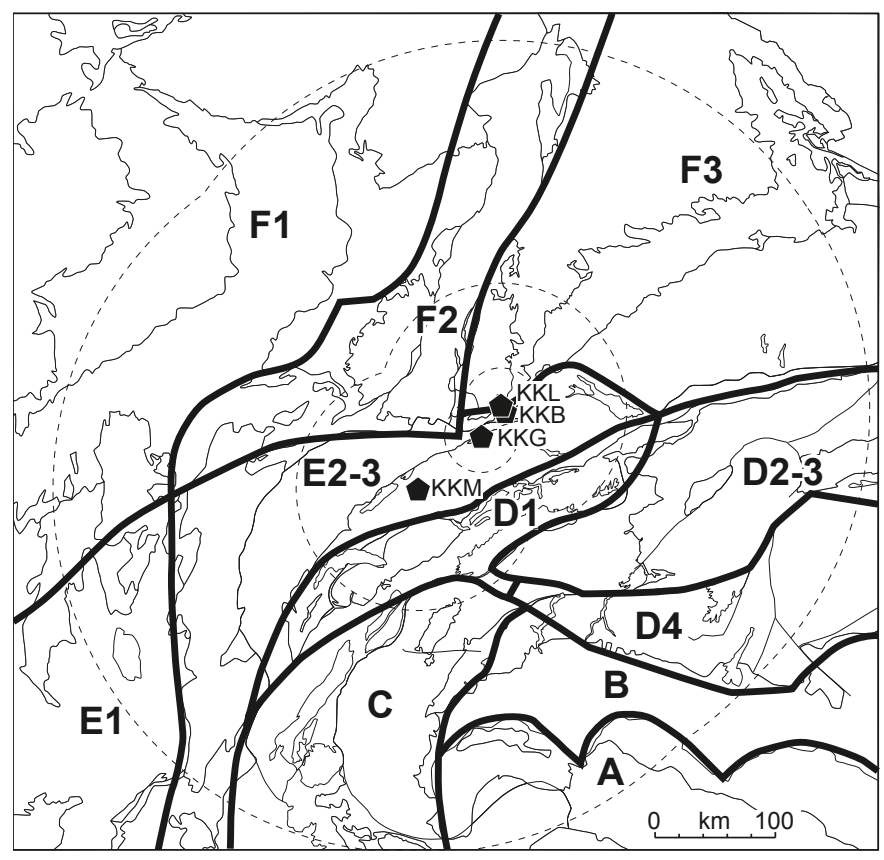

Fig. 14. Map of the Macro-Zones (MZs) introduced for the completeness analysis and the computation of the seismicity parameters used in the PSHA.
The analysis on completeness of the national catalogues is based on information from the catalogue compilers and from so-called Stepp-plots (Stepp 1972). The analysis of completeness periods shown in Fig. 15a reveals that, with a few exceptions, all catalogues show similarities in the estimated completeness periods. Similarly, the analysis grouping data into MZs, again based on histograms of seismicity rate and on Stepp-plots, points to similarities amongst the MZs regarding the evaluated completeness periods (Fig. 15b). Since the available data are not sufficient for a reliable assessment of completeness for some of the MZs, the choice of the completeness periods has to mainly rely on evaluations of larger national catalogue zones and/or on extrapolations from neighbouring MZs.

\subsection{Evaluation of $b$-values}

As is the case for catalogue completeness analysis, SZs are considered to be too small for the evaluation of $b$-values. Therefore $b$-values are evaluated according to two alternative approaches for larger areas. In a first approach the $b$-values were obtained from MZs, in a second approach $b$-values were computed for the national catalogue zones by avoiding the mixing of data from different national catalogues. Subsequently, the $b$-values obtained by the two alternative approaches were compared by taking into account their uncertainties. The final $b$-values for the MZs are obtained as a weighted average of the two estimates by expert judgement.

\subsubsection{Evaluation of b-values for the individual Macro-Zones}

Sub-catalogues have been extracted for each MZ from the de-clustered ECOS catalogue and seismicity rates have been computed according to the Albarello \& Mucciarelli (2002) approach. This approach evaluates the probability that each 5-year segment of the catalogue is complete and it weights this accordingly in the global seismicity rate assessment on a statistical basis. Therefore, it is not very sensitive on the completeness of the individual catalogues constituting ECOS. The $b$-values are determined by using both least square (LS) and the maximumlikelihood (ML) approaches with the estimated seismicity rates (see discussion about the performance of these approaches in Slejko et al. 2008). As the rates computed according to the Albarello \& Mucciarelli (2002) approach are based on the whole catalogue data, the time period covered by each sub-catalogue is considered as complete and it enters into the estimation of the $b$-value standard deviation. An exception to this rule is applied only for the magnitude 6.9 class (moment magnitude $M w$ of the Basel earthquake according to the ECOS). In this case the paleoseismological information is also used, indicating one event every 2000 years.

The number of earthquakes treated within each $\mathrm{MZ}$ varies strongly and this of course conditions the quality of the results obtained. MZ E1 collects only 28 earthquakes and MZ B collects only 85 events. Thus, for these MZs the quality of the re-

138 S. M. Schmid \& D. Slejko 

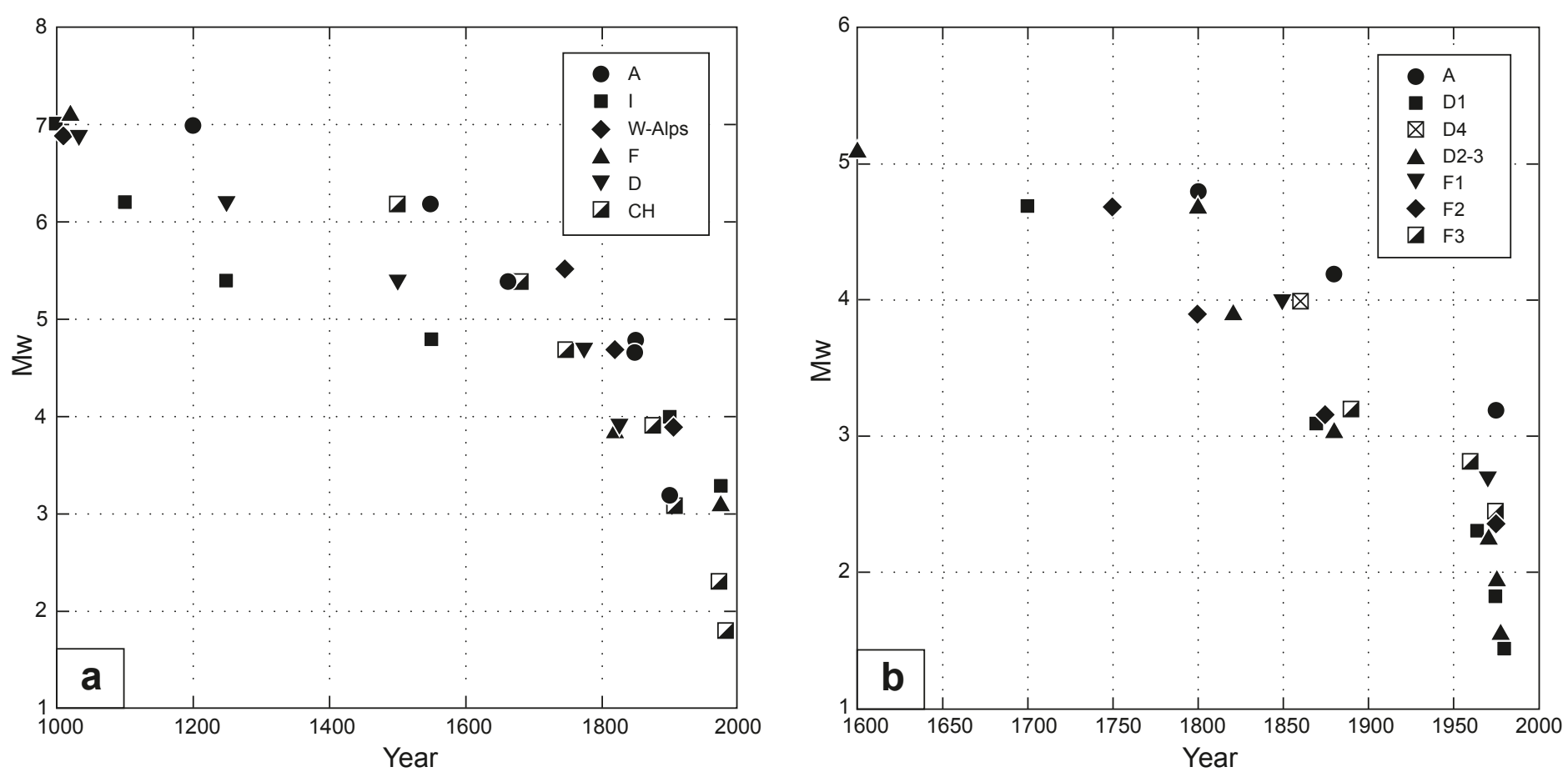

Fig. 15. Analysis of completeness periods. The location of the symbols indicates after which starting year catalogue information concerning seismicity above a given threshold magnitude $M_{W}$ is considered as complete in the respective national catalogues (Fig. 15a: A = Austria, I = Italy, W-Alps = Western Alps, $\mathrm{F}=$ France, $\mathrm{D}=$ Germany, $\mathrm{CH}=$ Switzerland) and within the respective MZs (Fig. 15b) as defined in Fig. 14.

sults is questionable. All the other MZs contain more than 240 earthquakes, and in 5 cases their number even exceeds 1000.

Seismicity rates, binned over 0.3 magnitude units, are associated with given magnitudes when establishing the Gutenberg-Richter relationship according to the procedure described below. The most delicate part of the procedure is the choice of the minimum magnitude considered for the analysis (magnitude threshold) since this determines the number of seismicity rates used for the $b$-value estimation. In a first trial all the data from the magnitude with the highest associated seismicity rate were chosen. This should be the least complete class. When a large difference was encountered between the $b$-values calculated by using the LS and ML approaches a threshold magnitude was introduced by an evaluation of the seismicity rate graphs by eye. The seismicity rates show a nice linear alignment only in the case of MZs D1 and F1, for which no introduction of a magnitude threshold is needed, the resulting $b$-value being well constrained. In some other cases the differences were notable, but sometimes the choice of the magnitude threshold turned out to be questionable (for example in case of MZ B).

There is a possibility that systematic errors may arise when mixing magnitude values obtained from historical and instrumental periods in the ECOS catalogue. This is because the conversion of historical data, often based on intensity evaluations, is notoriously difficult. In order to explore this possibility, separate analyses have been performed additionally for all the MZs. For seven amongst them (A, C, D1, E2-3, F1, F2, F3) out of a total of 11 MZs the $b$-value could be reasonably well es- tablished. Fig. 16 derived for MZ F2, which contains the source of the Basel earthquake, is a good example for this. However, in the case of, for example, MZ D2-3 the average $b$-value has a large uncertainty (Fig. 17). For MZs B and D4 the $b$-value calculated for the historical seismicity is considered as the best estimate. MZ E1 collects a too small number of events; hence, a valid result cannot be obtained by the above method and we have to rely on estimates from the larger national catalogue zones discussed in the next section. The results obtained from the global analysis of the Gutenberg-Richter graphs are reported in Table 1.

\subsubsection{Evaluation of $b$-values for national catalogue zones}

The definition of the eleven MZs for computing $b$-values is a logical consequence of wanting to create zones sufficiently large to include enough earthquakes for reliable and representative $b$-values, but based entirely on amalgamations of subsets of the previously defined SZs (Figs. 8 and 9). As a result, the MZs straddle different national earthquake catalogues, each with different magnitudes of completeness as a function of time (Fig. 15a). In order to assess the degree to which spatial heterogeneity of catalogue completeness within a single MZ might bias the resulting $b$-values, we chose to follow an additional alternative approach, based on a zonation, which more closely follows the boundaries of the national catalogues. Subsequently, we compare the results obtained from the two approaches (MZs vs. catalogue zones) and define the final $b$-val- 

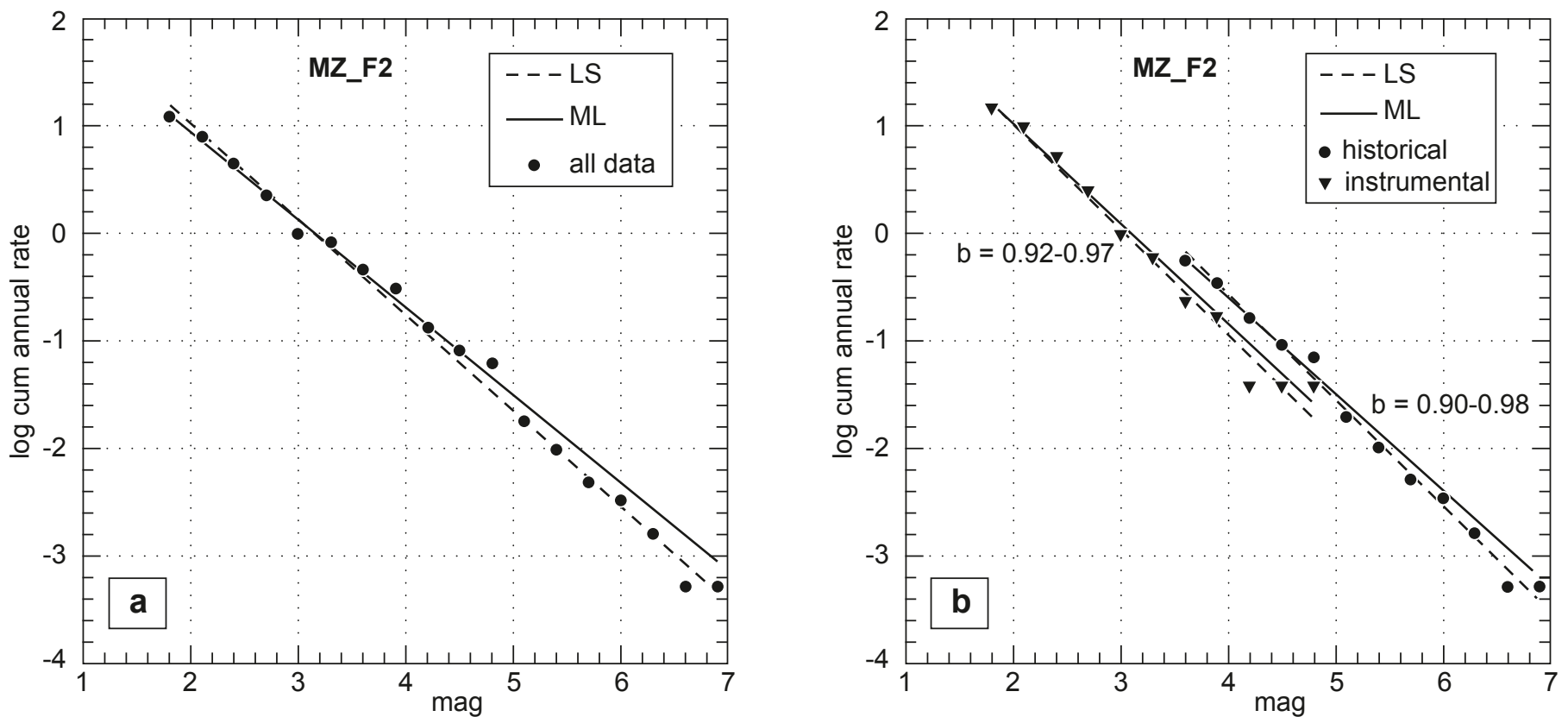

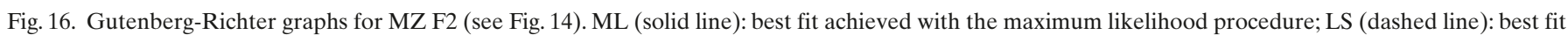
achieved with the least squares procedure. a) All data; b) separate best fits for historical (circles) and instrumental (triangles) time periods.

ues used for each MZ and its standard deviation to be used for PSHA (Table 1).

We start from the premise that spatial variations of $b$-values occur smoothly and that they are only statistically resolvable on the basis of a large number of events from a very homogeneous catalogue. Thus, the bias in $b$-values derived for zones that follow catalogue boundaries, which then can be assigned to seismotectonically defined source zones, is possibly smaller than the uncertainty associated with $b$-values derived directly for zones with problems of catalogue completeness.
Assuming that ECOS is both more complete and more homogeneous for Switzerland and the immediate surroundings (the southernmost part of the Rhine Graben), we further subdivided this area into a few smaller zones (Basel, northern Switzerland, eastern Switzerland, Wallis, Swiss Alps), in order to check for possible spatial variations. For the wider surroundings of Switzerland we stick more or less to national boundaries, with the exception of the area of the Western Alps, which straddles Italian, French and Swiss catalogues, and is seismically more active than the other regions south and southwest of Switzerland.

Table 1. Comparison between the different calculated $b$-values and final $b$-values proposed for each Macro-Zone. Note that the final choice of the $b$-value is an expert judgement weighted average value, as described in the text.

\begin{tabular}{|c|c|c|c|c|c|c|c|}
\hline MZ & CAT & $b$-CAT & $\sigma \boldsymbol{b}-\boldsymbol{C A T}$ & $b-\mathbf{M Z}$ & $b$-MZ range & $b$ & $\sigma \boldsymbol{b}$ \\
\hline A & I & 1.0 & 0.1 & 0.96 & $0.92-1.00$ & 0.96 & 0.1 \\
\hline B & I & 1.0 & 0.1 & 1.00 & $0.78-1.00$ & 1.00 & 0.1 \\
\hline $\mathrm{C}$ & $\mathrm{F}, \mathrm{I}, \mathrm{CH}$ & 1.0 & 0.1 & 0.78 & $0.72-0.82$ & 0.92 & 0.1 \\
\hline D2-3 & $\mathrm{CH}, \mathrm{A}$ & 1.0 & 0.1 & 0.88 & $0.85-0.90$ & 0.94 & 0.1 \\
\hline D4 & $\mathrm{I}, \mathrm{CH}$ & 1.0 & 0.1 & 1.00 & $0.99-1.03$ & 1.00 & 0.1 \\
\hline E1 & $\mathrm{F}$ & 0.94 & 0.1 & & $0.68-0.90$ & 0.95 & 0.1 \\
\hline $\mathrm{F} 2$ & $\mathrm{D}, \mathrm{CH}, \mathrm{F}$ & $0.88-0.94$ & 0.1 & 0.91 & $0.89-0.93$ & 0.90 & 0.1 \\
\hline F3 & $\mathrm{D}$ & 0.94 & 0.1 & 0.81 & $0.79-0.85$ & 0.88 & 0.1 \\
\hline
\end{tabular}

$\mathrm{MZ}=$ Macro-Zone. CAT $=$ dominating national catalogue(s) for the MZ. $b$-CAT $=b$-value for CAT(s). A direct association of CAT to MZ is problematic but can drive the choice. $\sigma b$-CAT $=$ standard deviation of $b$-value. $b$-MZ $=b$-value for a given $\mathrm{MZ} . b$-MZ range $=$ range of possible $b$-values for a given $\mathrm{MZ}$; $b=$ final $b$-value proposed; $\sigma b=$ standard deviation of chosen $b$-value. 
In calculating $b$-values for the Swiss and German regions, the apparent rate change during the second half of the 20th century is again taken into account. Whether this reflects a true fluctuation in seismic activity, or whether it is an artefact due to the transition from macroseismic data to instrumental magnitudes, is irrelevant for $b$-value calculations. In both cases it introduces a bias that should be corrected for. In fact, the results show that ignoring this effect leads to poor fits of the regressions and to relatively low $b$-values. So for the German and Swiss data, we calculate separate $b$-values for the historic and instrumental periods.

All calculations of $b$-values are made with an implementation of the ML method that accounts for periods of variable catalogue completeness (Weichert 1980). In the plots of the magnitude vs. frequency data, the activity rates and cumulative rates are binned over 0.3 magnitude values and adjusted according the assumed completeness periods for each magnitude interval. The calculated standard deviations given for each $b$-value are not a realistic measure of the uncertainty of the results, since they cannot account for possible errors in the catalogues or for possible deviations of the data from the underlying model assumptions. An indication of this fact was found from the examination of the differences between $b$-values obtained from instrumental and macroseismic data for each zone. The mean of these discrepancies (standard deviation, $\sigma$ ) is about 0.1 , whereas most of the calculated $\sigma \mathrm{s}$ are between 0.03 and 0.08 . Thus a $\sigma$ of the resulting $b$-values on the order of 0.1 is more realistic (see Table 1 ).

The average values seem to suggest a small but systematic difference in the $b$-value between the Alps (1.0) and their foreland (0.89). On the other hand, the difference between the Valais (0.96) and eastern Switzerland (1.01) is probably not significant, in particular considering that the historic data from the Wallis deviate strongly from an ideal Gutenberg-Richter relationship.

Considering that the $b$-values calculated for the zones in Austria (0.98) and the Western Alps (0.89) are poorly constrained and that these zones are tectonically similar to the Swiss Alps, it is in principle possible to assign the corresponding $b$-value (1.0) to the entire Alpine domain. The $b$-value of 1.02 obtained from the more conservative completeness assessment of the Italian zone is also insufficiently well constrained, so that the $b$-value of 1.0 could apply to this zone as well. The $b$-value obtained for France (0.85) is based on an eyeball fit to very little data, and there is no evident seismotectonic reason for eastern France to be significantly different from the rest of the more distant Alpine foreland. Therefore the same $b$-value for both the French and German zones (0.94) appears as a more plausible proposal.

\subsubsection{Conclusions regarding $b$-values for hazard calculations}

In a first step, and in order to compare the $b$-values based on a zonation that follows national catalogue boundaries to the $b$-values obtained for the seismotectonically defined MZs, the
Table 2. Seismic source sets for recurrence parameters.

\begin{tabular}{|c|c|c|c|}
\hline Sources with correlated & $b$-value & Seismicity Rate Altern & tives \\
\hline A & $0.96 \pm 0.1$ & $\begin{array}{l}\text { All data } \\
\text { All data, larger mag }\end{array}$ & $\begin{array}{l}\text { (wt } 0.5 \text { ) } \\
\text { (wt } 0.5 \text { ) }\end{array}$ \\
\hline B & $1.00 \pm 0.1$ & $\begin{array}{l}\text { All data } \\
\text { All data, larger mag }\end{array}$ & $\begin{array}{l}\text { (wt } 0.5 \text { ) } \\
\text { (wt } 0.5 \text { ) }\end{array}$ \\
\hline $\mathrm{C} 1, \mathrm{C} 2, \mathrm{C} 3$ & $0.92 \pm 0.1$ & $\begin{array}{l}\text { All data } \\
\text { All data, larger mag }\end{array}$ & $\begin{array}{l}\text { (wt } 0.5) \\
\text { (wt } 0.5)\end{array}$ \\
\hline $\begin{array}{l}\text { D1a, D1b, D1c, D1e, D1f, } \\
\text { D1bcd, D1bcde, D1de }\end{array}$ & $0.93 \pm 0.1$ & $\begin{array}{l}\text { Instrumental data } \\
\text { Historical data } \\
\text { Hist. data, larger mag }\end{array}$ & $\begin{array}{l}\text { (wt } 0.333 \text { ) } \\
\text { (wt } 0.334 \text { ) } \\
\text { (wt } 0.333\end{array}$ \\
\hline D2, D3a, D3b & $0.94 \pm 0.1$ & $\begin{array}{l}\text { Instrumental data } \\
\text { Historical data } \\
\text { Hist. data, larger mag }\end{array}$ & $\begin{array}{l}\text { (wt } 0.333 \text { ) } \\
\text { (wt } 0.334) \\
\text { (wt } 0.333 \text { ) }\end{array}$ \\
\hline $\mathrm{D} 4 \mathrm{a}, \mathrm{D} 4 \mathrm{~b}, \mathrm{D} 4 \mathrm{c}$ & $1.00 \pm 0.1$ & $\begin{array}{l}\text { All data } \\
\text { All data, larger mag }\end{array}$ & $\begin{array}{l}\text { (wt } 0.5 \text { ) } \\
\text { (wt } 0.5 \text { ) }\end{array}$ \\
\hline E1 & $0.95 \pm 0.1$ & $\begin{array}{l}\text { All data } \\
\text { All data, larger mag }\end{array}$ & $\begin{array}{l}\text { (wt } 0.5 \text { ) } \\
\text { (wt } 0.5 \text { ) }\end{array}$ \\
\hline $\begin{array}{l}\text { E2a, E2b, E2c, E2d, E2e, } \\
\text { E2cde, FF, E2dF2f, E2eF2f, } \\
\text { E2cdeF2f, E2n, E2s, E2f, } \\
\text { E3a, E3aF2f, E3b }\end{array}$ & $0.89 \pm 0.1$ & $\begin{array}{l}\text { For E2a, E2b: } \\
\text { All data } \\
\text { All data, larger mag } \\
\text { For rest of sources: } \\
\text { Instrumental data } \\
\text { Historical data } \\
\text { Hist. data, larger mag }\end{array}$ & $\begin{array}{l}\text { (wt } 0.5 \text { ) } \\
\text { (wt } 0.5 \text { ) } \\
\text { (wt } 0.333 \text { ) } \\
\text { (wt } 0.334 \text { ) } \\
\text { (wt } 0.333 \text { ) }\end{array}$ \\
\hline F1a, F1b, F2c & $0.95 \pm 0.1$ & $\begin{array}{l}\text { All data } \\
\text { All data, larger mag }\end{array}$ & $\begin{array}{l}\text { (wt } 0.5 \text { ) } \\
\text { (wt } 0.5 \text { ) }\end{array}$ \\
\hline $\begin{array}{l}\text { F2a, F2b, F2b_RF, RF, } \\
\text { F2bpcy, F2bF2f, F2d, F2e, } \\
\text { F2f }\end{array}$ & $0.90 \pm 0.1$ & $\begin{array}{l}\text { Instrumental data } \\
\text { Historical data } \\
\text { Hist. data, larger mag }\end{array}$ & $\begin{array}{l}\text { (wt } 0.333 \text { ) } \\
\text { (wt } 0.334 \text { ) } \\
\text { (wt } 0.333 \text { ) }\end{array}$ \\
\hline F3a, F3aF2f, F3b, F3c & $0.88 \pm 0.1$ & $\begin{array}{l}\text { Instrumental data } \\
\text { Historical data } \\
\text { Hist. data, larger mag }\end{array}$ & $\begin{array}{l}\text { (wt } 0.333 \text { ) } \\
\text { (wt } 0.334 \text { ) } \\
\text { (wt } 0.333 \text { ) }\end{array}$ \\
\hline
\end{tabular}

$b$-values derived from the national catalogues are assigned to the individual MZs:

1) Alps and southern foreland of the Alps (MZs A, B, C, D1, D2-3, D4): $b=1.0 \pm 0.1$;

2) Northern and Western Alpine foreland (MZ E2-3): $b=0.89 \pm 0.1$

3) Rhine Graben including Basel (MZ F2): $b=0.88-$ $0.94 \pm 0.1$

4) German and French distal Alpine foreland (MZs E1, F1, $\mathrm{F} 3): b=0.94 \pm 0.1$.

The $b$-values cited above are also reported in Table 1 (column $b$-CAT), together with their standard deviation (column $\sigma b$ CAT). In the same table, those calculated for the MZs identify a $b$-value range (column $b$-MZ range) obtained by the analysis of the different results (ML and LS methods; whole, historical, and instrumental periods) inside which a preferred value was extracted (column $b$-MZ). 

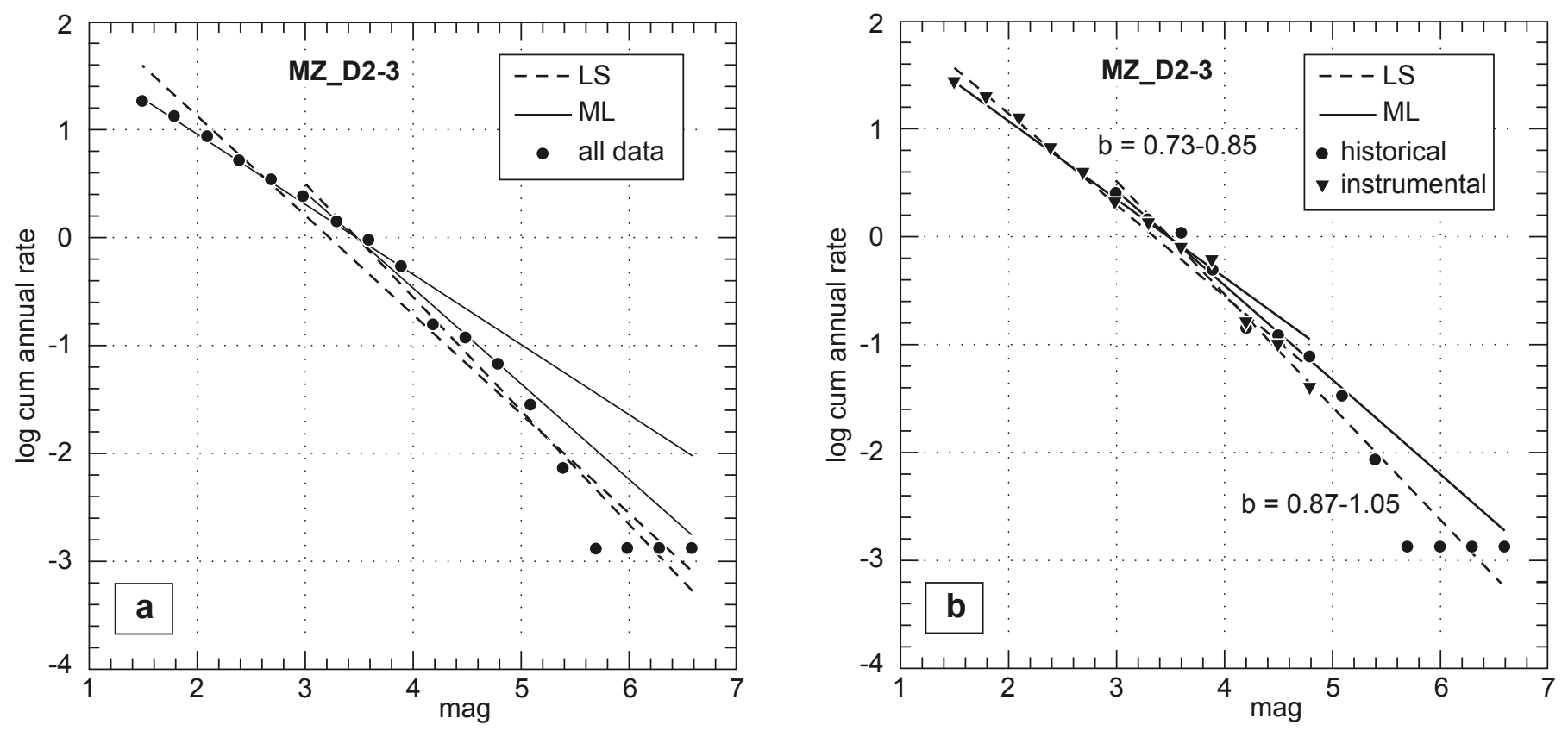

Fig. 17. Gutenberg-Richter graphs for MZ D2-3 (see Fig. 16 for abbreviations and symbols).

As can be seen from Table 1, the agreement between the two methods of estimating $b$, derived from completely different considerations, is quite good. Hence, the final $b$-value chosen takes into account all the considerations previously described and, especially, the quality of the data available in each MZ. This final choice should be seen as a sort of "expert judgement weighted average" value. The same value of 0.1 , chosen as $\sigma$ (column $\sigma b$ ) for all MZs, quantifies the uncertainty associated with this final estimate from all the detailed considerations reported above.

In summary, a node with 3 branches (mean $b$-value minus one $\sigma$, mean $b$-value, mean $b$-value plus one $\sigma$ ) is introduced into the logic tree shown in Fig. 18 in order to adequately take into account the uncertainties associated to the computation of $b$-values. The actual $b$-values used are listed in Table 2 .

\subsection{Evaluation of the seismicity rates}

The seismicity rates of $M_{W} 5.0$, in addition to the $b$-values, were used to characterize the seismicity of each SZ according to the truncated Gutenberg-Richter relation. These seismicity rates were extrapolated from those of the threshold magnitude of each SZ, which were calculated by using a modification of the ML approach outlined in Weichert (1980). The modifications of this approach include (a) variable magnitude bin widths, (b) use of different complete periods for different regions, and (c) use of a fixed $b$-value. The rate calculations are performed for each of the SZs (Figs. 8 and 9) on the basis of the de-clustered earthquake catalogue and by using the final $b$-values listed in Table 1. However, the $1356 \mathrm{Basel}$ event is additionally included in the calculation, with a return period of 2000 years and for all zones that contain this event.

Preliminary calculations showed that for several SZs the data (in particular the historical data) significantly deviate from the ideal Gutenberg-Richter relation. In those cases the best fit achieved with the ML procedure (ML-fit) tends to be anchored by the more numerous low-magnitude events and fails to match the higher magnitudes. The deviation from a good fit is somewhat systematic in the sense that when the fit is poor, the observed cumulative number of high-magnitude events is almost invariably higher than that predicted by the Gutenberg-Richter relation. This could be due to two reasons. A first reason could be that the Gutenberg-Richter relation and the fixed $b$-values derived from the MZs are not a good model for the earthquake recurrence in Switzerland and surroundings. The second reason could be that the (truncated) Gutenberg-Richter relation holds over the entire range of magnitudes, but that the data quality is not sufficiently good in order to reflect this. Because there are no well-developed faults in the area for which we would expect that they feature large characteristic earthquakes, that occur more frequently than predicted by the low magnitude events, the first explanation is considered unlikely.

This leaves the possibility of the existence of a systematic magnitude bias in the historical data between low- and highmagnitude events. Such a bias could have entered the catalogue through the way in which the intensity information was converted into $M_{W}$ : events that were listed in the old Swiss earthquake collections with an intensity of at least VI EMS were completely re-evaluated and $M_{W}$ was determined from an analysis of the entire macroseismic field. The magnitudes of

142 S. M. Schmid \& D. Slejko 


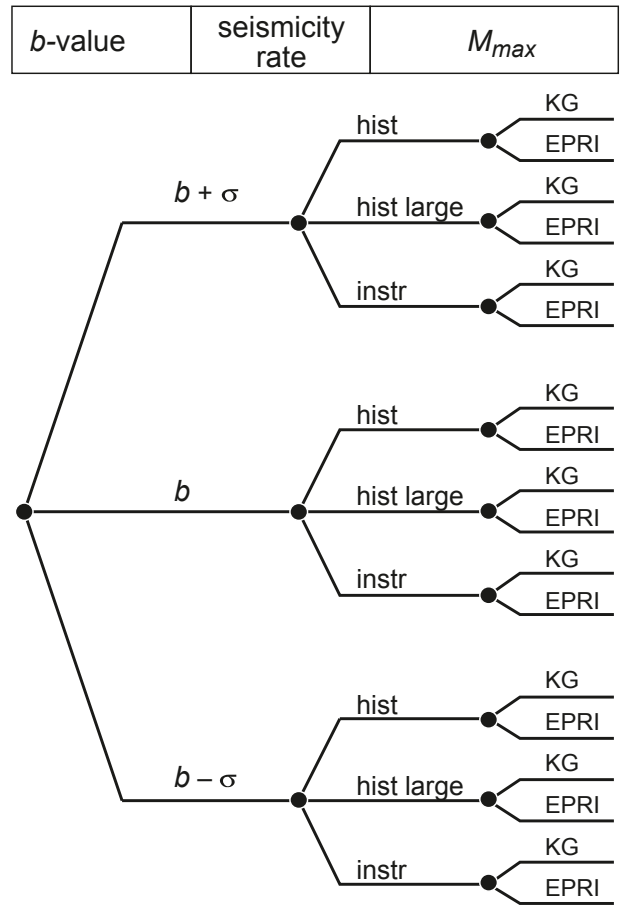

Fig. 18. Logic tree used for inferring the Gutenberg-Richter parameters describing seismicity rates and for inferring maximum magnitude $M_{\max }$ for individual SZs. Node $b$-value: mean $b$-value minus one $\sigma$, mean $b$-value, mean $b$-value plus one $\sigma$. Node seismicity rate: branch "hist" includes all pre-1975 events, branch "hist large" includes pre-1975 events with larger magnitudes, "instr" includes post 1975 events only; for SZs outside Switzerland and Germany the rate node was simplified into 2 options: all data and all data with larger magnitudes. Node $M_{\max }$ : KG: Kijko \& Graham (1998) method; EPRI Johnston et al. (1994) method.

the weaker events, on the other hand, were calculated from a simple regression between observed intensity and magnitudes. Since in this case there is no objective basis for deciding whether the magnitudes of the stronger events have been overestimated (alternative 1) or whether the magnitudes of the weaker ones have been underestimated (alternative 2), it is reasonable to consider both cases. Given that the unweighted ML regression tends to be anchored at the more numerous smaller events, this approach covers the first alternative. To account for the second alternative, we consider a ML regression that is restricted to larger magnitudes. This cut-off is justified by the fact that in the general conversion formula used for ECOS, epicentral intensity VI approximately corresponds to $M_{W} 4.7$. Given the fact that the revision of the old catalogue certainly resulted in several events being reclassified to lower intensities and given the general uncertainty involved in all these earthquake size estimates, a threshold of $M_{W} 4.3$ is considered appropriate.

In addition, the already cited apparent change in activity rate during the time period 1970-1975, visible in the Swiss and German data, is likely to have an important influence on the resulting seismicity rates. Either there is an error in the cata- logue or alternatively, it is an expression of a natural fluctuation of seismic activity. In either case, it is necessary to perform the computations separately for the post-1975 instrumental period and the pre-1975 macroseismic period when estimating $a$-values for the SZs covered by the Swiss and German catalogues.

In the end, three branches concerning the seismicity rates have been introduced for the SZs in Switzerland and southern Germany into the logic tree shown in Fig. 18: (1) branch "hist" (pre-1975 with all events), (2) branch "hist large" (pre1975 events with larger magnitudes and (3) "instr" (post-1975 events). Each of these branches has a weight of one third, whereas for all other SZs we have only the first two branches, each with a weight of one half (Table 2, Seismicity Rate Alternatives).

Only after all the $b$-values were fixed for the SZs inside an MZ, was the problem of attributing the seismicity rates to the individual SZs addressed. This is illustrated by the graph of Fig. 19, which depicts the frequency of events with $M_{W}$ equal to, or larger than, 5 for each SZ, computed considering the mean $b$-value and only the pre-1975 events with the larger magnitudes (branch "hist large"; i.e.: 4.3 with the exceptions of D1f, where it is $3.1 ; \mathrm{D} 4 \mathrm{a}$, where it is $3.5 ; \mathrm{D} 2, \mathrm{D} 4 \mathrm{c}$, and FF, where it is 3.9; E2e, E2eF2, F2a, and F2e, where it is 4.7; and E2b, where it is 5.4). The uncertainty of the seismicity rates of $M_{W} 5.0$ was associated statistically.

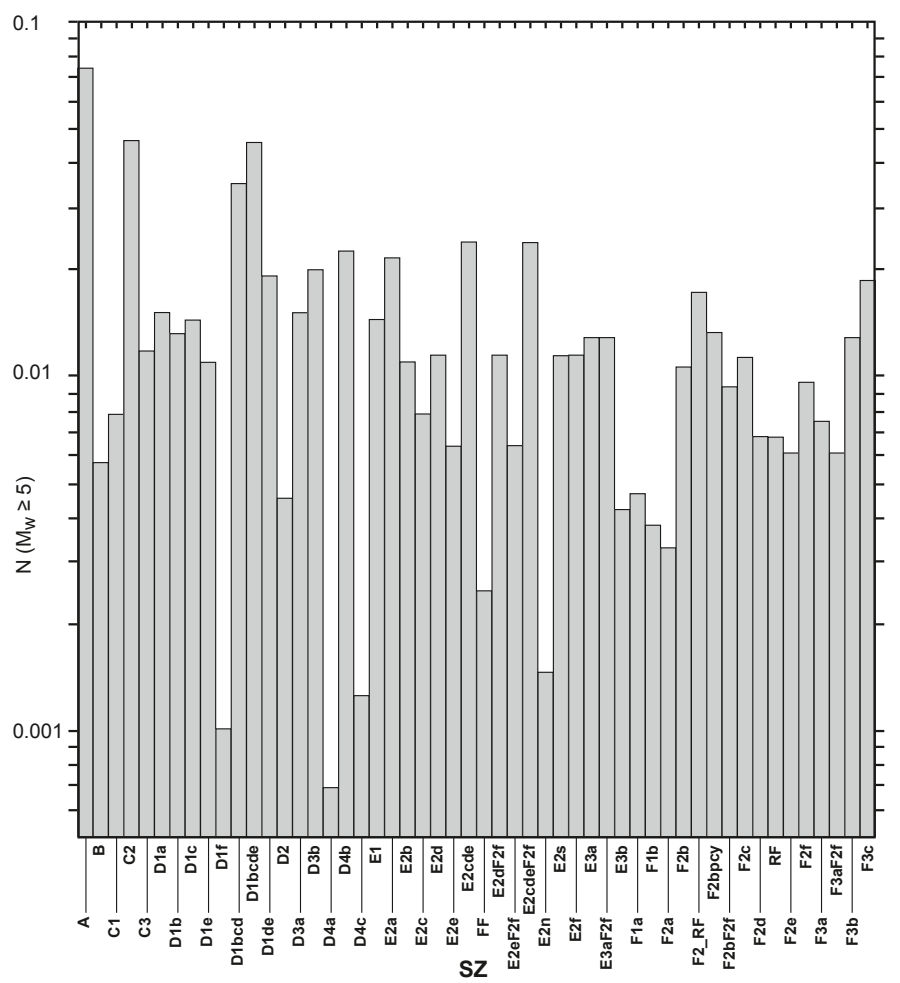

Fig. 19. Annual number of earthquakes $(\mathrm{N})$ with a magnitude $\left(M_{W}\right)$ larger than, or equal to, 5 in the different SZs. 
Table 3. Geological estimates of $M_{\max }$.

\begin{tabular}{|c|c|c|c|c|c|c|}
\hline $\mathbf{M Z}$ & SZ & $L_{\max }(\mathbf{k m})$ & Tectonic element & Remarks & SRL (km) & $\boldsymbol{M}_{G}$ \\
\hline A & & 100 & & & $40 \pm 10$ & $6.9 \pm 0.3$ \\
\hline $\mathrm{B}$ & & 100 & & & $40 \pm 10$ & $6.9 \pm 0.3$ \\
\hline $\mathrm{C}$ & & 100 & & & $40 \pm 10$ & $6.9 \pm 0.3$ \\
\hline D1 & D1a & 100 & Rhone strike slip fault & & $40 \pm 10$ & $6.9 \pm 0.3$ \\
\hline D1 & D1b-D1f & 100 & & & $40 \pm 10$ & $6.9 \pm 0.3$ \\
\hline D2 & & 100 & & & $40 \pm 10$ & $6.9 \pm 0.3$ \\
\hline D3 & D3a & 100 & Engadine line & & $40 \pm 10$ & $6.9 \pm 0.3$ \\
\hline D3 & $\mathrm{D} 3 \mathrm{~b}$ & 100 & Inntal line & & $40 \pm 10$ & $6.9 \pm 0.3$ \\
\hline D4 & & 100 & Giudicarie, Tonale, Pustertal lines & & $40 \pm 10$ & $6.9 \pm 0.3$ \\
\hline E1 & & 100 & & & $40 \pm 10$ & $6.9 \pm 0.3$ \\
\hline E2 & $\mathrm{E} 2 \mathrm{a}, \mathrm{E} 2 \mathrm{~b}$ & 100 & Bresse graben & & $40 \pm 10$ & $6.9 \pm 0.3$ \\
\hline E2 & $\mathrm{E} 2 \mathrm{c}$ & 100 & Pontarlier fault & & $40 \pm 10$ & $6.9 \pm 0.3$ \\
\hline E2 & $\mathrm{E} 2 \mathrm{~d}$ & 100 & Fribourg fault & & $40 \pm 10$ & $6.9 \pm 0.3$ \\
\hline $\mathrm{E} 2$ & $\mathrm{E} 2 \mathrm{e}$ & 20 & & subsurface Molasse data & $8 \pm 2$ & $6.1 \pm 0.3$ \\
\hline E2 & E2f & 100 & PC-trough & & $40 \pm 10$ & $6.9 \pm 0.3$ \\
\hline E2 & $\mathrm{E} 2 \mathrm{n}$ & 50 & Rheingraben-type faults & & $20 \pm 5$ & $6.6 \pm 0.3$ \\
\hline E2 & $\mathrm{E} 2 \mathrm{~s}$ & 100 & PC-trough & subsurface Molasse data & $40 \pm 10$ & $6.9 \pm 0.3$ \\
\hline E3 & E3a & 50 & & subsurface Molasse data & $20 \pm 5$ & $6.6 \pm 0.3$ \\
\hline E3 & $\mathrm{E} 3 \mathrm{~b}$ & 100 & PC-trough & & $40 \pm 10$ & $6.9 \pm 0.3$ \\
\hline $\mathrm{F} 1$ & & 100 & & & $40 \pm 10$ & $6.9 \pm 0.3$ \\
\hline $\mathrm{F} 2$ & & 200 & Rhinegraben & & $80 \pm 20$ & $7.3 \pm 0.3$ \\
\hline $\mathrm{F} 3$ & & 50 & pre-existing faults $\mathrm{E}$ of Rhinegraben & & $20 \pm 5$ & $6.6 \pm 0.3$ \\
\hline
\end{tabular}

Table 4. $M_{\max }$ estimates for the MZs. Note that the tail of the $M_{\max }$ distributions at very high magnitudes was cut off according to the geologically derived $M_{G}$.

\begin{tabular}{llllllll}
\hline $\mathbf{M Z}$ & $\boldsymbol{M}_{\boldsymbol{X}}$ & $\boldsymbol{M}_{\boldsymbol{K}}$ & $\sigma \boldsymbol{M}_{\boldsymbol{K}}$ & $\boldsymbol{M}_{\boldsymbol{E}}$ & $\sigma \boldsymbol{M}_{\boldsymbol{E}}$ & $\boldsymbol{M}_{\boldsymbol{G}}$ & $\sigma \boldsymbol{M}_{\boldsymbol{G}}$ \\
\hline A & 6.3 & 6.3 & 0.2 & 6.3 & 0.1 & 6.9 & 0.3 \\
B & 5.3 & 5.3 & 0.2 & 6.2 & 0.6 & 6.9 & 0.3 \\
C & 6.4 & 6.5 & 0.2 & 6.5 & 0.2 & 6.9 & 0.3 \\
D1 & 6.4 & 6.6 & 0.3 & 6.4 & 0.2 & 6.9 & 0.3 \\
D2-3 & 6.5 & 6.6 & 0.2 & 6.6 & 0.2 & 6.9 & 0.3 \\
D4 & 6.2 & 6.2 & 0.2 & 6.3 & 0.4 & 6.9 & 0.3 \\
E1 & 5.8 & 6.1 & 0.3 & 6.2 & 0.4 & 6.9 & 0.3 \\
E2-3 & 5.8 & 5.8 & 0.2 & 5.8 & 0.1 & 6.9 & 0.3 \\
F1 & 6.2 & 6.5 & 0.3 & 6.3 & 0.3 & 6.9 & 0.3 \\
F2 & 6.9 & 7.1 & 0.3 & 7.0 & 0.2 & 7.3 & 0.3 \\
F3 & 5.8 & 5.8 & 0.2 & 5.9 & 0.2 & 6.6 & 0.3 \\
\hline
\end{tabular}

$\mathrm{MZ}=$ macro zone, $M_{X}=$ maximum observed magnitude, $M_{K}=$ Kijko and Graham (1998) maximum magnitude, $\sigma M_{K}=$ error on Kijko and Graham (1998) maximum magnitude, $M_{E}=$ EPRI maximum magnitude, $\sigma M_{E}=$ error on EPRI maximum magnitude, $M_{G}=$ geological maximum magnitude, $\sigma M_{G}=$ error on geological maximum magnitude.

It can be seen from Fig. 19 that the seismicity rates are very different from one SZ to another but it must be pointed out that they refer to the whole SZ area, which varies remarkably in size. These seismicity rates, together with the $b$-values and the $M_{\max }$ values, identify the truncated Gutenberg-Richter relations which describe the seismicity inside each SZ.

\subsection{Maximum earthquake magnitude}

Two statistical approaches, the so-called EPRI approach (Johnston et al. 1994) and the one proposed by Kijko \& Graham (1998), as well as a geological approach (Wells \& Coppersmith 1994) have been considered for the assessment of maximum magnitude $M_{\max }$. The $M_{\max }$ distributions were developed for the larger MZs and then applied to the SZs within each MZ. The reason for calculating $M_{\max }$ for MZs rather than for individual SZs is given by the fact that $M_{\max }$ is often a characteristic of the wider geological environment rather than that of well-localized individual faults. Moreover, $M_{\max }$ can be better assessed on the basis of a rich earthquake catalogue than on few events recorded in a limited portion of crust.

The geological estimates (Wells \& Coppersmith 1994) provide an upper bound (or cut-off value) for the distribution of $M_{\max }$ calculated by the two statistical approaches. For this purpose we estimate the maximum fault surface length $\left(L_{\max }\right)$ within each SZ based on geological arguments, as well as its surface rupture length (SRL), which can be reactivated during an earthquake. SRL corresponds to between 30 and $50 \%$ of $L_{\max }$. In some of the SZs, $L_{\max }$ cannot really be estimated on geological grounds due to the lack of data. Approximate estimates of $L_{\max }$ equal to $100 \mathrm{~km}$ are plausible in other areas. $L_{\max }$ larger than $100 \mathrm{~km}$ can only be postulated for the Rhine Graben area (MZ F2). The case of the Rhine Graben is unique, in that the presence of through-going single fault segments with a length of up to $200 \mathrm{~km}$ cannot be completely excluded, in contrast to all the other regions. The Wells \& Coppersmith (1994) relation 
between SRL (for all types of faults) and $M_{\max }$ is applied to the SZs and the results for the geology-based values of $M_{\max }\left(M_{G}\right)$ are reported in Table 3 for all SZs.

Table 4 summarizes the maximum magnitudes that are computed according to the two statistical approaches (the Kijko \& Graham 1998 and the EPRI Johnston et al. 1994 approaches), referred to as $M_{K}$ and $M_{E}$, respectively. In the case of the Kijko \& Graham (1998) approach, the exact formulation proposed by Armando Cisternas (personal communication) is used in order to calculate the values of $M_{K}$. This modification replaces the original approximation used by Kijko \& Graham (1998). The total length of the catalogue for each MZ is taken as complete over the period of the catalogue within which the seismicity parameters are assessed. This is because the Albarello \& Mucciarelli (2002) approach, which was used to compute the seismicity parameters, weights the different time segments according to the automatically computed completeness. As can be seen from Table 4 , the values of $M_{K}$ are notably larger $(+0.3)$ compared to the value of the maximum observed magnitude $M_{X}$ only in a few cases. This is because the observation period considered to be around 1000 years is very long. By considering shorter completeness periods the difference would progressively increase.

When using the EPRI (Johnston et al. 1994) approach, we choose the distribution of $M_{\max }$ in "extended crust" as the prior distribution for all MZs, with the exception of E1, F1, and F3, for which a "non-extended crust" is considered. The latter MZs were not affected by Mesozoic or Cenozoic rifting while the rest of the MZs suffered intensive rifting before they were involved in Alpine orogeny. To identify the peak of the distribution, a small magnitude bin size (0.1) is used to pinpoint $M_{\max }$ between 5.0 and $M_{G}$. In the $M_{\max }$ computation it is possible to take into account the possible error in magnitude estimates reported in the catalogue (Tinti \& Mulargia 1985). Some tests performed have shown that generally the effect of this option consists in a lowering of the $M_{\max }$ estimate. It was decided, then, not to take into account the event magnitude error in the computation. The results obtained, in terms of the $M_{\max }$ value with the highest probability, are also reported in Table 4 (column $M_{E}$ ). The estimates are rather sensitive to the completeness periods chosen and to the number of earthquakes within a given MZ. For this reason, the completeness periods have been modified in 3 cases in order to take into account the maximum observed earthquake that would otherwise have been excluded. In the EPRI approach the prior magnitude significantly shapes the final probability distribution. The maximum magnitude exceeds the maximum observed magnitude by a large amount only in two cases. In MZ B the difference between the two values is 0.9 while in MZ E1, which is poorly documented by the catalogue data the difference is 0.4 .

In general, both approaches give results that do not differ much from the maximum observed magnitude. The estimates obtained with the Kijko \& Graham (1998) approach seem more robust but they depend very strongly on the maximum observed magnitude. The geologically derived $M_{G}$ are indepen- dent from the catalogue data and larger because they represent extreme values in the sense that a possible reactivation of an entire pre-existing fault length is considered, regardless of the past record in the catalogues. Only in the case of MZ B do the two statistical approaches differ significantly. In a few cases $M_{G}$ is much larger when compared to the other two estimates; MZ E2-3 is a good example for this. There, the statistical maxima are around 5.8 while $100 \mathrm{~km}$-long faults do exist, and hence, magnitudes around 6.9 cannot be excluded. This shows that the time period captured by catalogue length is possibly not long enough for predicting large earthquakes.

The results obtained for $M_{\max }$ and their standard deviation are used to construct an exponential distribution for $M_{\max }$. This distribution is discretized in 0.5 magnitude unit bins to develop weights on alternative values of $M_{\max }$. For both approaches, the tail of the $M_{\max }$ distributions at very high magnitudes is cut off according to the geologically derived $M_{G}$. This cut-off ensures that physically impossible high magnitude events are excluded from the subsequent hazard calculations. This is based on the premise that nature provides a set of pre-existing faults that may rupture over a given percentage of their total length during one single event.

In summary both the Kijko \& Graham (1998) as well as the EPRI (Johnston et al. 1994) approaches have been applied and have produced two alternative branches in the logic tree (Fig. 18). Since we are unable to judge which approach is more suitable for the study area, equal weight is given to both these approaches. These alternative branches are calculated for all MZs. The resulting distributions are cut off at $M_{G}$. Subsequently, these $M_{\max }$ distributions are exported into the individual SZs contained within a given MZ.

\section{Summary}

The PEGASOS project represents a key experience for PSHA in Europe. Special attention is paid to the quantification of epistemic uncertainties involved in the computational processing by the use of a logic tree (Fig. 7). It turns out that the definition of the seismogenic sources is of prime importance. The work summarized in this paper is the contribution of one of the four teams involved in the process of source definition and proposes a multitude of alternative seismic source configurations, largely based on geological data and seismotectonic investigations. As the ground motion with an extremely low probability of exceeding a given threshold value is requested for the design of nuclear power plants, a very comprehensive investigation had to be done for the identification of all sources, which show a reasonable probability to be active or re-activated in the near future.

The analysis develops in a cascade fashion, and the territory under study is first partitioned into NKPs (Fig. 5), then into SRs (Fig. 6), and at the end, into area seismic sources referred to as SZs (Figs. 8 and 9). Only in very special cases is it found necessary to define linear seismic sources (i.e. faults). Given the fact that the area of investigation is part of a very diffuse plate 
boundary region, area sources referred to as SZs have to be designed in the majority of the cases. Figs. 8 and 9 pinpoint two different seismogenic scenarios. This takes into account the most relevant epistemic uncertainty, namely the question weather pre-existing Permo-Carboniferous troughs are considered as prone to present-day reactivation or not. For the case that these troughs are not considered to be prone for re-activation, further alternatives are explored for line and area sources in the Basel area, the Alpine foreland, and within the Alps. At the end, all the alternatives considered for the SZ geometry define a logic tree with 21 branches (Fig. 7), and their likelihood is established by expert opinion.

As some SZs do not collect enough earthquakes for computing robust seismicity parameters (mainly the $b$-value of the Gutenberg-Richter relation and $M_{\max }$ ), they are merged together into wider MZs, whose $b$-values and $M_{\max }$ are computed in different ways. Conversely, the seismicity rates are assessed on the basis of the SZ seismicity. Considerations about the uncertainties related to the definition of the SZ seismic potential (in terms of seismicity rates, $b$-values, and $M_{\max }$ ) lead to the definition of a logic tree with 18 branches (Fig. 18).

The final logic tree (a combination of the logic trees depicted in Figs. 6 and 18) has $378(21 \times 18)$ branches and represents the seismic source characterization input into PSHA that properly takes into account both epistemic and aleatory uncertainties.

\section{Acknowledgements}

We particularly acknowledge the input of Nicholas Deichmann who was the third scientist of our team; his contribution during all phases of the project was very important. The source characterization part of the PEGASOS project was co-ordinated by Kevin Coppersmith (Coppersmith Consultants) and Bob Youngs (Geomatrix), who greatly helped us all along the work. Many thanks are due to Bob Youngs for the computation of the $a$-values and for making available some software. Moreover, we want to thank NAGRA, mainly represented by the person of Christian Sprecher. Many colleagues working for Proseis AG, particularly Jim Farrington, René Graf, and Philippe Roth are thanked for all the technical and logistic support they offered during the three years of the project. Stefan Schmid acknowledges financial support by the Swiss "Staatssekretariat für Bildung und Forschung" for financial support within the framework of the EUCOR-URGENT project initiated by Peter Ziegler (Binningen) and lively exchange of ideas with his colleague Kamil Ustaszewski (Basel, now Taipei). Peter Nievergelt (Basel) is thanked for re-drawing the figures. The manuscript profited from a very constructive review by Carlo Meletti. We thank swissnuclear and NAGRA for the permit to publish parts of the PEGASOS study. Last but not least this contribution was written in order to honour our friend and colleague Martin Burkhard who tragically died in 2006. We had many exciting and often controversial discussions with Martin, who was a prominent member of one of the PEGASOS expert teams.

\section{REFERENCES}

Albarello, D. \& Mucciarelli, M. 2002: Seismic hazard estimates using ill-defined macroseismic data at site. Pure and Applied Geophysics 159, 1289-1304.

Ambraseys, N.N., Simpson, K.A. \& Bommer, J.J. 1996: Prediction of horizontal response spectra in Europe. Earthquake Engineering Structural Dynamics 25, 371-400.

Baer, M., Deichmann, N., Braunmitter, J., Husen, S., Fäh, D., Giardini, D., Kästli, Ph., Kradolfer, U. \& Wiemer, S. 2005: Earthquakes in Switzerland and surrounding regions during 2004. Eclogae Geologicae Helvetiae 98, 407-418.
Becker, A. 1999: In Situ Stress data from the Jura mountains - new results and interpretation. Terra Nova 11, 9-15.

Becker, A. 2000:The Jura Mountains - an active foreland fold-and-thrust belt? Tectonophysics 321, 381-406.

Becker, A., Ferry, M., Monecke, K., Schnellmann, M. \& Giardini, D. 2005: Multiarchive paleoseismic record of late Pleistocene and Holocene strong earthquakes in Switzerland. Tectonophysics 400, 153-177.

Birkhäuser, Ph., Roth, Ph., Meier, B. \& Naef, H. 2000: 3D-Seismik: Räumliche Erkundung der mesozoischen Sedimentschichten im Zürcher Weinland. NAGRA Technischer Bericht 00-03.

Burkhard, M. 1990: Aspects of the large-scale Miocene deformation in the most external part of the Swiss Alps (Subalpine Molasse to Jura fold belt). Eclogae Geologicae Helvetiae 83, 559-583.

Burkhard, M. \& Sommaruga, A. 1998: Evolution of the western Swiss Molasse basin: Structural relations with the Alps and the Jura belt. In Mascle C. et al. (Eds.): Cenozoic Foreland Basins of Western Europe. Geological Society Special Publications 134, 279-298.

Burkhard, M. \& Grünthal, G. 2009: Seismic source zone characterization for the seismic hazard assessment project PEGASOS by the Expert Group 2 (EG1b). Swiss Journal of Geosciences 102, 149-188.

Ceriani, S., Fügenschuh, B. \& Schmid, S.M. 2001: Late-stage thrusting at the "Penninic Front" in the Western Alps between Mont Blanc and Pelvoux massifs. International Journal of Earth Sciences 90, 685-702.

Coppersmith, K.J. \& Youngs, R.R. 1986: Capturing uncertainty in probabilistic seismic hazard assessments within intraplate environments. In: Proceedings of the Third U.S. National Conference on Earthquake Engineering, August 24-28, 1986, Charleston, SC, Earthquake Engineering Research Institute, El Cerrito CA U.S.A. Volume 1,301-312.

Coppersmith, K.J., Youngs, R.R. \& Sprecher, Ch. 2009: Methodology and main results of seismic source characterization for probabilistic seismic hazard analysis: the PEGASOS project, Switzerland. Swiss Journal of Geosciences 102, 91-105.

Cornell, C.A. 1968: Engineering seismic risk analysis. Bulletin Seismological Society America 58, 1583-1606.

Deichmann, N. 2002: Seismotectonic constraints on possible ground motions in Switzerland. Unpublished PEGASOS SP-2 Workshop of 17. 4. 2002.

Deichmann, N., Ballarin Dolfin, D. \& Kastrup, U. 2000: Seismizität der Nordund Zentralschweiz. Nagra Technischer Bericht NTB 00-05. Nagra, Wettingen.

Dèzes, P., Schmid, S.M. \& Ziegler, P.A. 2004: Evolution of the European Cenozoic Rift System: interaction of the Alpine and Pyrenean orogens with their foreland lithosphere. Tectonophysics 389, 1-33.

Eva, E., Solarino, C., Eva, C. \& Neri, G. 1997: Stress tensor orientation derived from fault plane solutions in the southwestern Alps. Journal of Geophysical Research 102, 8171-8185.

Fäh, D., Giardini, D., Bay,F., Bernardi, F., Braunmiller, J., Deichmann, N., Furrer, M., Gantner, L., Gisler, M., Isenegger, D., Jimenez, M.J., Kastli P., Koglin R., Masciadri, V., Rutz, M., Scheidegger, C., Schibler, R., Schorlemmer, D., Schwarz-Zanetti, G., Steimen, S., Sellami, S., Wiemer, S. \& Wossner, J. 2003: Earthquake catalogue of Switzerland (ECOS) and the related macroseismic database. Eclogae Geologicae Helvetiae 96, 219-236.

Franck, P.,Wagner, J.-J.,Escher, A.\& Pavoni, N.1984:Évolution des contraintes téctoniques et sismicité dans la région du col du Sanetsch, Alpes valaisannes helvétiques. Eclogae Geologicae Helvetiae 77, 383-393.

Fügenschuh, B. \& Schmid, S.M. 2003: Late stages of deformation and exhumation of an orogen constrained by fission track data: A case study in the Western Alps. Geological Society of America Bulletin 115, 1425-1440.

Gardner, J.K. \& Knopoff, L. 1974: Is the sequence of earthquakes in southern California, with aftershocks removed, Poissonian? Bulletin Seismological Society America 64, 1363-1367.

Giamboni, M., Ustaszewski, K., Schmid, S.M., Schumacher, M.E. \& Wetzel, A. 2004: Plio-Pleistocene transpressional reactivation of Paleozoic and $\mathrm{Pa}-$ leogene structures in the Rhine-Bresse transform zone (northern Switzerland and eastern France). International Journal of Earth Sciences 93: 207-223.

Giardini, D., Grünthal, G. Shedlock, K.M. \& Zhang, P.Z. 1999: The GSHAP Global Seismic Hazard Map. Annali Geofisica 42, 1225-1230.

146 S. M. Schmid \& D. Slejko 
Giardini, D., Wiemer, S., Fäh, D. \& Deichmann, N. 2004: Seismic hazard assessment of Switzerland 2004. Swiss Seismological Service, ETH Zurich, 94 pp.

Grellet, B.,Combes, P., Granire, T.\& Philip, H.1993:Sismotectonique de la France métropolitaine dans son cadre géologique et géophysique. Mémoires de la Société Géologique de France 164, volume 1 \& 2, 76 pp, 24 tables, 1 map.

Grünthal, G. 1985: The up-dated earthquake catalogue for the German Democratic Republic and adjacent areas - Statistical data characteristics and conclusions for hazard assessment. In: Proceedings 3rd International Symposium on the Analysis of Seismicity and Seismic Risk. Czechoslovakian Academy of Sciences Prague, 19-25.

Grünthal, G., Mayer-Rosa, D. \& Lenhardt, W.A. 1998: Abschätzung der Erdbebengefährdung für die D-A-CH-Staaten - Deutschland, Österreich, Schweiz. Bautechnik 10, 753-767.

Jiménez, M.J. \& Pavoni, N. 1984: Focal mechanisms of recent earthquakes 1976-1982 and seismotectonics in Switzerland. In: Stiller H. and Ritsema A. (Eds): Proceedings of Session 12 European Geodynamics, Seismicity and Seismic Hazard (poster session) presented at the XVIII. General Assembly of the IASPEI. Zentralinstitut für Physik der Erde, Potsdam, 77-84.

Jiménez, M.-J., Giardini, D. \& Grünthal, G. + SESAME Working Group 2001: Unified Seismic hazard modelling throughout the Mediterranean region. Bollettino di Geofisica Teorica ed Applicata 42,3-18.

Jiménez, M.-J., Giardini, D. \& Grünthal, G. 2003: The ESC-SESAME Unified Hazard Model for the European-Mediterranean Region. EMSC/CSEM Newsletter 19, 2-4.

Johnston, A.C., Coppersmith, K.J., Kanter, L.R. \& Cornell, C.A. 1994: The earthquakes of stable continental regions. Volume 1: Assessment of Large Earthquake Potential. EPRI, Palo Alto CA. U.S.A., 62 pp.

Jordan, P. 1992: Evidence for large-scale decoupling in the Triassic evaporites of Northern Switzerland: An overview. Eclogae Geologicae Helvetiae 85, 677-693.

Kastrup, U. 2002: Seismotectonics and stress field variations in Switzerland. PhD thesis ETH Zürich No. 14527, 153 pp.

Kastrup, U., Zoback, M.L., Deichmann, N., Evans, K.F., Giardini, D. \& J. Michael, A.J. 2004: Stress field variations in the Swiss Alps and the northern Alpine foreland derived from inversion of fault plane solutions. Journal of Geophysical Research 109, B01402, doi:10.1029/2003JB002550.

Kastrup, U., Deichmann, N., Fröhlich, A. \& Giardini, D. 2007: Evidence for an active fault below the northwestern Alpine foreland of Switzerland. Geophysical Journal International 169, 1273-1288.

Kijko, A. \& Graham, G. 1998: Parametric-historic procedure for probabilistic seismic hazard analysis. Part I: estimation of maximum regional magnitude $\mathbf{M}_{\max }$. Pure and Applied Geophysics 152, 413-442.

Kissling, E. 2007: Towards a plate tectonic model of Alpine orogeny. Abstract, key note presentation, 8th Int. Workshop on Alpine Geological Studies, Davos, Switzerland, 10th-12th October 2007.

Kulkarni, R.B., Youngs, R.R. \& Coppersmith, K.J. 1984: Assessment of confidence intervals for results of seismic hazard analysis. In: Proceedings of the Eighth World Conference on Earthquake Engineering, July 21-28, 1984, San Francisco CA U.S.A.. Prentice-Hall Inc., Englewood Cliffs NJ U.S.A. Vol. 1, 263-270.

Laubscher, H. 1961: Die Fernschubhypothese der Jurafaltung. Eclogae Geologicae Helvetiae 54, 222-282.

Laubscher, H. 1972: Some overall aspects of Jura dynamics. American Journal of Science 272, 293-304.

Laubscher, H. 1992: Jura kinematics and the Molasse basin. Eclogae Geologicae Helvetiae 85, 653-675.

Laubscher, H. 2006: Zur Geologie des Erdbebens von Basel. In: Meier W. (Ed.): Da verfiele Basel überall. 184. Neujahrsblatt der GGG Basel, Schwabe Verlag Basel, 207-230.

Laubscher, H. 2007: The 1356 earthquake: What do we really know? Bulletin für angewandte Geologie 12/1, 21-27.

Lopes Cardozo, G.G.O. \& Granet, M. 2003: New insight in the tectonics of the southern Rhine Graben-Jura region using local earthquake seismology. Tectonics 22, 1078, doi:10.1029/2002TC001442.

Madritsch, H., Schmid, S. M. \& Fabbri O. 2008: Interactions between thin- and thick-skinned tectonics at the northwestern front of the Jura fold-andthrust belt (eastern France). Tectonics, doi:10.1029/2008TC002282.
Marchant, R., Ringgenberg, Y., Stampfli, G., Birkhäuser, Ph., Roth, Ph. \& Meier, B. 2005: Paleotectonic evolution of the Zürcher Weinland (northern Switzerland), based on 2D and 3D seismic data. Eclogae Geologicae Helvetiae 98, 345-362.

Maurer, H.R., Burkhard, M., Deichmann, N. \& Green, A.G. 1997: Active tectonism in the central Alps: Contrasting stress regimes north and south of the Rhone valley. Terra Nova 9, 91-94.

Mayer-Rosa, D. \& Müller, St. 1979: Studies of seismicity and selected focal mechanisms in Switzerland. Schweizerische Mineralogische Petrographische Mitteilungen 59, 127-132.

McGuire, R.K. 1977: Seismic design spectra and mapping procedures using hazard analysis based directly on oscillator response. Earthquake Engineering Structural Dynamics 5, 211-234.

McGuire, R.K. \& Shedlock, K.M. 1981: Statistical uncertainties in seismic hazard evaluations in the United States. Bulletin Seismological Society America 71, 1287-1308.

Meghraoui, M., Delouis, B., Ferry, M., Giardini, D., Huggenberger, P., Spottke, I. \& Granet, M. 2001: Active Normal Faulting in the Upper Rhine Graben and Paleoseismic Identification of the 1356 Basel Earthquake. Science 293, 2070-2073.

Meletti, C., Patacca, E. \& Scandone, P. 2000: Construction of a seismotectonic model: the case of Italy. Pure and Applied Geophysics 157, 1135 .

Meyer, B.P. 1994a: Untere Süsswassermolasse des zentralen und östlichen Mittellandes: Regionale Interpretation bestehender Seismik und petrophysikalische Interpretation von Fremd- und Eigenbohrungen. Unpublished NAGRA Interner Bericht 94-27.

Meyer, B.P. 1994b: Untere Süsswassermolasse des westlichen Mittellandes: Regionale Interpretation bestehender Seismik und petrophysikalische Interpretation von Fremdbohrungen. Unpublished NAGRA Interner Bericht 94-28.

Monecke, K., Anselmetti, F.S., Becker, A., Schnellmann, M., Sturm, M. \& Giardini, D. 2006: Earthquake-induced deformation structures in lake deposits: A Late Pleistocene to Holocene paleoseismic record for Central Switzerland. Eclogae Geologicae Helvetiae 99, 343-362.

Muir-Wood, R. 1993: From global seismotectonics to global seismic hazard. Annali di Geofisica 36, 153-168.

Müller, St. 1984a: Dynamic processes in the Alpine arc. Annales Geophysicae 2, 161-164.

Müller, St. 1984b: Tiefenstruktur, Dynamik und Entwicklung des Mittelmeerund Alpenraumes. Vierteljahrsschrift der Naturforschenden Gesellschaft in Zurich 129, 217-245.

Müller, St. \& Mayer-Rosa, D. 1980: The new seismic hazard maps for Switzerland. Revista Geofisica 13, 7-19.

Müller, W.H., Blümling, P. \& Becker, A. 1987: Die Entkoppelung des tektonischen Spannungsfeldes an der Jura-Überschiebung. Eclogae geologicae Helvetiae 80, 473-489.

Müller, W.H., Naef, H. \& Graf, H.R. 2002: Geologische Entwicklung der Nordschweiz, Neotektonik und Langzeitszenarien, Zürcher Weinland. NAGRA Technischer Bericht 99-08. NAGRA, Wettingen, 226 pp.

Musson, R.M.V., Sellami,S. \& Brüstle, W. 2009: Preparing a seismic hazard model for Switzerland: The view from PEGASOS Expert Group 3 (EG1c). Swiss Journal of Geosciences 102, 107-120.

NAGRA 2004: Probabilistic Seismic Hazard Analysis for Swiss Nuclear Power Plant Sites (PEGASOS Project) prepared for Unterausschuss Kernenergie der Überlandwerke (UAK). Final Report Vol. 1-6, 2557 pp. To be obtained on request at swissnuclear by writing to info@swissnuclear.ch.

Pavoni, N. 1961: Faltung durch Horizontalverschiebung. Eclogae Geologicae Helvetiae 54, 515-534.

Pavoni, N. 1977: Erdbeben im Gebiet der Schweiz. Eclogae Geologicae Helvetiae $70,351-370$

Pavoni, N. 1980a: Comparison of focal mechanisms of earthquakes and faulting in the Helvetic zone of the central Valais, Swiss Alps. Eclogae Geologicae Helvetiae 73, 551-558.

Pavoni, N. 1980b: Crustal stresses inferred from fault-plane solutions of earthquakes and neotectonic deformation in Switzerland. Rock Mechanics Suppl. 9, 63-68. 
Plenefisch, T. \& Bonjer, K.-P. 1997: The stress field in the Rhine Graben area inferred from earthquake focal mechanisms and estimation of frictional parameters. Tectonophysics 275, 71-97.

Reasenberg, P.A. 1985: Second-order moment of central California seismicity. Journal of Geophysical Research 90, 5479-5495.

Rebez,A. and Slejko, D. 2004: Introducing epistemic uncertainties into seismic hazard assessment for the broader Vittorio Veneto area (N.E. Italy). Bollettino di Geofisica Teorica ed Applicata 45, 305-320.

Rüttener, E. 1995: Earthquake hazard evaluation for Switzerland. Matériaux pour la Géologie de la Suisse, Géophysique No 29. Commission Suisse de Géophysique \& Schweizerischer Erdbebendienst Zürich, 106 pp.

Sägesser, R. \& Mayer-Rosa, D. 1978: Erdbebengefährdung in der Schweiz. Schweizerische Bauzeitung SIA, 3-18.

Schmid, S.M., Pfiffner, O.A., Froitzheim, N., Schönborn, G., \& Kissling, E. 1996: Geophysical-geological transect and tectonic evolution of the SwissItalian Alps. Tectonics 15, 1036-1064.

Schmid, S.M. \& Kissling, E. 2000: The arc of the Western Alps in the light of geophysical data on deep crustal structure. Tectonics 19, 62-85.

Schmid, S.M., Fügenschuh, B., Kissling, E. \& Schuster, R. 2004a: Tectonic map and overall architecture of the Alpine orogen. Eclogae geologicae Helvetiae 97, 93-117.

Schmid, S.M., Fügenschuh, B., Kissling, E. \& Schuster, R. 2004b:TRANSMED Transects IV, V and VI: Three lithospheric transects across the Alps and their forelands. In: Cavazza W., Roure F., Spakman W., Stampfli G.M. \& Ziegler P.A. (Eds.): The TRANSMED Atlas: The Mediterranean Region from Crust to Mantle. Springer Verlag.

Schnellmann, M., Anselmetti, F., Giardini, D. \& McKenzie, J. 2006: 15’000 years of mass-movement history in Lake Lucerne: Implications for seismic and tsunami hazards. Eclogae geologicae Helvetiae 99, 409428.

Schumacher, M. 2002: Upper Rhine Graben: Role of preexisting structures during rift evolution. Tectonics 21, 1006, doi10.1029/2001TC900022.

Schwartz, D.P. \& Coppersmith, K.J. 1984: Fault behaviour and characteristic earthquakes: examples from the Wasatch and San Andreas faults. Journal of Geophysical Research 89, 5681-5698.

SIA 2003: Norm SIA261- Einwirkungen auf Tragwerke, Schweizerischer Ingenieur und Architekten Verein.

Slejko, D., Peruzza, L. and Rebez,A. 1998: Seismic hazard maps of Italy. Annali di Geofisica 41, 183-214.

Slejko, D., Rebez, A. and Santulin, M. 2008: Seismic hazard estimates for the Vittorio Veneto broader area (N.E. Italy). Bollettino di Geofisica Teorica ed Applicata 49, 329-356.

SSHAC (Senior Seismic Hazard Analysis Committee) 1997: Recommendations for probabilistic seismic hazard analysis: guidance on uncertainty and use of experts. NUREG/CR-6372, Lawrence Livermore National Laboratories Livermore, $256 \mathrm{pp}$.

Stepp, J.C. 1972: Analysis of completeness of the earthquake sample in the Puget Sound area and its effect on statistical estimates of earthquake hazard. In: Proceedings of the International Conference on Microzonation volume 2,897-910.

Stepp, J.C., Wong, I., Whitney, J., Quittmeyer, R., Abrahamson, N., Toro, G. Youngs, R., Coppersmith, K., Savy, J., Sullivan, T. \& Yucca Mountain PSHA Project Members 2001: Probabilistic seismic hazard analyses for ground motion and fault displacement at Yucca Mountain, Nevada Earthquake Spectra 17, 113-151.

Sue, Ch., Thouvenot, F. \& Fréchet, J. 1999: Widespread extension in the core of the Western Alps revealed by earthquake analysis. Journal Geophysical Research 104, B11, 25611-25622.

Swiss Seismological Service 2002: PALEOSEIS, Reconstructing the paleoseismological record in northern Switzerland. Final report to HSK and NAGRA of 30.06.2002, 28 pp.

Tesauro, M., Hollenstein, C., Egli, R., Geiger, A. \& Kahle, H.-G. 2005: Continuous GPS and broad-scale deformation across the Rhine Graben and the Alps. International Journal of Earth Sciences 94, 525-537, doi: 10.1007/ s00531-004-0453-0.

Tinti, S. \& Mulargia, F. (1985). Effects of magnitude uncertainties on estimating the parameters in the Gutenberg - Richter frequency - magnitude law. Bulletin Seismological Society America 75, 1681-1697.

Toro, G.R.,Abrahamson, N.A. \& Schneider, J.F. 1997: Model of strong motions from earthquakes in central and eastern North America: best estimates and uncertainties. Seismology Research Letters 68, 41-57.

Uhrhammer, R. 1986: Characteristics of northern and southern California seismicity. Earthquake Notes 57, 21.

Ustaszewski, K. \& Schmid, S.M. 2006: Control of preexisting faults on geometry and kinematics in the northernmost part of the Jura fold-and-thrust belt. Tectonics 25, TC5003, doi:10.1029/2005TC001915.

Ustaszewski, K. \& Schmid, S.M. 2007: Latest Pliocene to recent thickskinned tectonics at the Upper Rhine Graben - Jura Mountains junction. Swiss Journal of Geosciences Swiss Journal of Geosciences 100 293-312.

Ustaszewski, K., Schumacher, M.E., Schmid, S.M. \& Nieuwland, D. 2005a: Fault reactivation in brittle-viscous wrench systems - dynamically scaled analogue models and application to the Rhine-Bresse transfer zone. Quaternary Science Reviews 24,365-382.

Ustaszewski, K., Schumacher, M.E. \& Schmid, S.M. 2005b: Simultaneous normal faulting and extensional flexuring during rifting: an example from the southernmost Upper Rhine Graben. International Journal Earth Sciences 94, 680-696.

Waldhauser, F., Kissling, E., Ansorge, J. \& Müller, St. 1998: Three-dimensional interface modelling with two-dimensional seismic data: the Alpine crustmantle boundary. Geophysical Journal International 135, 264-278.

Weichert, D.H. 1980: Estimation of the earthquake recurrence parameters for unequal observation periods for different magnitudes. Bulletin Seismological Society America 70, 1337-1346.

Wells, D.L. \& Coppersmith, K.J.1994: New empirical relationship among magnitude, rupture length, rupture width, rupture area, and surface displacement. Bulletin Seismological Society America 84, 974-1002.

Wiemer, S., Garcia-Fernandez, M. \& Burg, J.-P. 2009: Development of a Seismic Source Model for probabilistic seismic hazard assessment of nuclear power plant sites in Switzerland. The view from PEGASOS Expert Group 4 (EG1d). Swiss Journal of Geosciences 102, 189-209.

Manuscript receivd June 5, 2008

Revision accepted September 29, 2008

Published Online first February 9, 2009

Editorial Handling: Stefan Bucher

148 S. M. Schmid \& D. Slejko 